\title{
Wage subsidies targeted to jobseekers with disabilities: subsequent employment and disability retirement
}

\author{
Nikolay Angelov ${ }^{1,2^{*}}$ and Marcus Eliason ${ }^{1}$ (D)
}

\author{
*Correspondence: \\ nikolay.i.angelov@gmail.com \\ ${ }^{1}$ Institute for Evaluation of Labour \\ Market and Education Policy (IFAU), \\ Box 513, S-751 20 Uppsala, Sweden \\ ${ }^{2}$ The Uppsala Center for Labour \\ Studies (UCLS), Uppsala University, \\ Box 513, S-751 20 Uppsala, Sweden
}

\begin{abstract}
In many countries, a non-negligible percentage of the working-age population has impairments that also entail reduced work capacity, and disability retirement is increasing. Despite this, studies on the effects of policies aimed at enhancing the labour market inclusion among people with disabilities, such as targeted wage subsidies, are surprisingly few. In an attempt to fill this gap, we have studied how wage subsidies affect future labour market outcomes for jobseekers with disabilities, in terms of employment and disability retirement. By using inverse probability weighting applied to rich Swedish register data, we contrast participants in the wage subsidy program to observably similar non-participants during a 19-year period. We find that participation was associated with both positive and negative labour market outcomes. On the negative side, participants were less likely to have unsubsidised employment. On the positive side, leaving the labour market through the disability insurance program was somewhat less common among participants. Moreover, using a broader employment measure including subsidised jobs, the participants were found to be employed to a larger extent, which could be interpreted either as locking-in effects or as fostering labour market inclusion.
\end{abstract}

JEL Classification: $\mathrm{C} 21$; J14; J23

Keywords: Disability, Wage subsidies, Subsidised employment, Disability insurance, Labour market programs

\section{Introduction}

The rising number of people on disability insurance in many countries, including Sweden, over the last decades calls for measures promoting labour market inclusion of people with disabilities (OECD 2010). In Sweden, disability insurance receipt increased to an all-time high of 10\% in 2006 (Swedish Social Insurance Agency 2014). Moreover, according to the Labour Force Surveys, $10 \%$ of the working age population in Sweden is reported to have some kind of impairment that entails reduced work capacity. ${ }^{1}$ Public expenditures on disability-related programs is substantial in many countries. In 2007, Sweden's expenditures amounted to $2.2 \%$ of GDP, a figure that, among the OECD countries, was only exceeded by Norway's $2.5 \%$ of GDP (OECD 2010).

Within this group, the labour force participation rate is only $50 \%$ and the unemployment rate is more than twice that for those without disabilities (Statistics Sweden 2009). Hence,

(c) The Author(s). 2018 Open Access This article is distributed under the terms of the Creative Commons Attribution 4.0 International License (http://creativecommons.org/licenses/by/4.0/), which permits unrestricted use, distribution, and reproduction in any medium, provided you give appropriate credit to the original author(s) and the source, provide a link to the Creative Commons license, and indicate if changes were made. 
people with disabilities face considerable difficulties in the labour market. ${ }^{2}$ To overcome some of the difficulties that people with disabilities face and to be able to reach the goalpresented in the United Nations Standard Rules for the Equalization of Opportunities of Persons with Disabilities-that people with disabilities should have the same opportunities to participate in working life as everyone else, special measures compensating for a reduced work capacity, such as wage subsidies, might be necessary.

Sweden has a long tradition of labour market policies targeted explicitly to jobseekers with disabilities-ranging from in-work aids to subsidised employmentaimed at strengthening their position in the labour market. The objective of the present study is to study empirically the relationship between participation in a wage subsidy program targeted to jobseekers with disabilities and future labour market outcomes in terms of employment and disability retirement. Targeted wage subsidies aim to stimulate labour demand by compensating for the workers' reduced work capacities or by reducing employers' uncertainties about particular jobseekers' work capacities. However, targeted wage subsidies can also play a stigmatising role by signalling a poorer work capacity than compensated for, ${ }^{3}$ and while the wage subsidies most often are time-limited, many jobseekers with disabilities have a permanently reduced work capacity. Hence, the impact of wage subsidies on the future labour market outcomes of jobseekers with disabilities is an open empirical question.

In an attempt to shed some light on this issue, we have identified all jobseekers with disabilities who participated in a wage subsidy program (lönebidrag) in 2000 and followed them during an 8-year pre-program period and a 10-year post-program period using Swedish register data. By applying inverse probability (of treatment) weighting (IPW) to rich administrative data, we have been able to compare this group to observably very similar jobseekers with disabilities who did not participate in the wage subsidy program. The two groups are not only nearly identical in terms of the usual background characteristics but also in terms of their 8-year labour market history (including, but not limited to, insured sickness absence and disability) and hospitalisation history. We have focused on two labour market outcomes: employment and disability retirement. While non-subsidised employment is the ultimate goal of the wage subsidy, it may nonetheless be an unrealistic goal given that the disability, along with the associated reduction in work capacity, in many cases is permanent or even deteriorating. For some, the realistic goal might instead be to be able to remain in subsidised employment over time. Likewise, disability retirement could also be viewed as an unwarranted (at least from a public policy perspective) but likely alternative outcome, especially in case of deteriorating work capacity. Given that the wage subsidy can be granted for 4 years and under certain circumstances, an even longer period, one would at least in the shorter run also expect considerable locking-in effects. ${ }^{4}$

We find that participants in the wage subsidy program had a much larger subsequent overall employment rate. In the year of (potential) program enrolment, the gap was as large as 54 percentage points. Obviously, most of this difference is mechanical and corresponds to the program participation per se. However, although the gap closed during the years that followed, a 11 percentage point difference remained after 10 years. When excluding subsidised jobs from the employment outcome measure, the picture changed dramatically. In the year of (potential) program enrolment, the employment rate 
was instead 21 percentage points lower among the participants than among the nonparticipants. After 2 years, the gap had closed to 11 percentage points and then vanished gradually. Hence, any positive employment effect of program participation seems to have been outweighed by considerable locking-in effects, not only in the short run but also in the longer run. We also found a lower percentage of disability insurance receivers among the participants than among the non-participants. While the percentage of disability insurance receivers among the participants was 2 points higher during the year of (potential) program enrolment and the next year, this gap had reversed by the third year and remained at about this level during the rest of the 10 -year period. Hence, the wage subsidy program seems to have promoted labour market inclusion somewhat by reducing the transition out of the labour force through the disability insurance program.

There are only a few previous empirical studies on wage subsidies targeted to jobseekers with disabilities. ${ }^{5}$ Due to the differences in study designs and outcomes, most of them are not comparable directly with this study. For example, several studies have focused on eligibility for wage subsidies, instead of actual participation in such a program. The findings from these studies seem to vary depending on the particular outcome under study: from negative or no effects on interview call-back rates (Deuchert and Kauer 2017; Baert 2016), no effects on disability insurance receipt (Gupta and Larsen 2010), to substantial positive effects on employment (Gupta and Larsen 2010). ${ }^{6} \quad 7 \quad 8$ Moreover, Gupta et al. (2015) found that lowering the subsidy level, in the same scheme as investigated in Gupta and Larsen (2010), decreased the number of subsidised employments, mainly through reduced hiring of subsidised workers. ${ }^{9}$

An exception is Jaenichen and Stephan (2011) whose findings make an interesting comparison to ours. They investigated the effectiveness of wage subsidies in Germany targeted to "hard-to-place" workers, which included unemployed jobseekers with disabilities. While they also found locking-in effects of the wage subsidy program, they report large positive effects on regular (non-subsidised) employment following the expiration of the subsidy (i.e. after 7-12 months). Three years after program enrolment, the employment rate was 25-42 percentage points higher among the participants than among the non-participants. These estimates are strikingly different from the large negative estimates found in the present study. Jaenichen and Stephan (2011) refer to this effect as the combined effect of receiving the wage subsidy and getting a job. In an attempt to isolate the effect of the wage subsidy (net of the effect of getting a job), they also provide estimates conditional on taking up a (subsidised or non-subsidised) job. Necessarily, this largely increased the initial and mechanical locking-in effect. However, for the period following the expiration of the subsidy, the estimates on regular (non-subsidised) employment are considerably smaller than the previously reported estimates of the combined effect of receiving the wage subsidy and getting a job, but they are still positive and statistically significant. ${ }^{10}$

The above discussion of the findings in Jaenichen and Stephan (2011) also highlights a probable reason for the scarce empirical evidence on the effects of wages subsidies targeted to jobseekers with disabilities. That is, it is exceedingly difficult, for several reasons, to identify the causal effect of participation. First, it is difficult to define an appropriate comparison group. This is mostly, but not exclusively, because participation in a wage subsidy program does not only imply participation in an active labour market program, but also implies becoming employed (with the wage subsidy). Second, the lack of objective 
and reliable measures of disability and work capacity makes it difficult to assess whether the study and comparison groups are, in fact, comparable. Third, it is difficult to identify the relevant outcome. Given that the disability, and the associated reduction in work capacity, in many cases is permanent, non-subsidised employment might not be a realistic goal. For some, the realistic goal might instead be to be able to remain in subsidised employment over time, but then a positive outcome becomes indistinguishable from participation in the program being evaluated. However, one might argue that given the many who are concerned by measures targeted to people with disabilities, and the size of the corresponding public expenditures, even descriptive evidence on the outcomes of these measures would be of policy relevance. Moreover, effect evaluations without exogenous variation in program assignment could instead provide additional analyses of how sensitive, or likely, the conclusions are to be explained by biases due to non-random assignment into the programs.

The paper proceeds with a brief description of the institutional settings in Section 2, including descriptions of the Public Employment Service's (PES's) coding of jobseekers as occupationally disabled, the targeted wage subsidy program, and the disability insurance program. We describe our data and outline our estimation strategy in Sections 3.1 and 3.2. In Section 4, we present our main results followed by several sensitivity analyses. Finally, Section 5 concludes the paper.

\section{Institutional background}

\subsection{Disabled jobseekers registered with the PES}

The target group for the wage subsidy program under study contains those who are registered as jobseekers at the PES and are deemed to have a functional impairment that entails reduced work capacity. The PES's system for coding and registration of occupational disability among jobseekers serves four purposes: (i) to ensure that the job seeker as early as possible receives adequate support in the job search process, (ii) to make the person eligible for special measures and programs targeted to jobseekers with disabilities, (iii) to facilitate planning and evaluation of the targeted measures, and (iv) to provide statistics for the estimation of resource needs (PES 2011).

The functional impairments and their associated reduction of work capacity are assessed by the caseworkers at the PES. In most cases, it relies on a medical report or a report from another specialist (e.g. a psychologist or speech therapist), but the caseworkers can also, if necessary to confirm the impairment and establish how it affects the conditions for work, consult the PES's own specialists. These specialists have a toolbox of methods including activity-based assessments of work capacity, work-related psychological investigations, and work-related social investigations. These methods include conversations and interviews, but also various test instruments. Finally, the caseworker, together with the jobseeker, makes a collective judgment concerning if and to what extent the impairment entails a reduced work capacity. If a reduced work capacity is established, an occupational disability code is recorded. The code will contain information on the specific impairment: cardio, vascular, and/or lung disease (code 11); hearing impairment and deafness (code 20); visual impairment (code 30); motor disability (code 40); other somatically related disabilities (code 51); mental disability (code 61); learning disability (code 71); socio-medical disability (code 81); asthma, allergy, and hypersensitivities (code 91); dyslexia and specific learning difficulties (code 92); and acquired brain injury (code 93). ${ }^{11}$ 


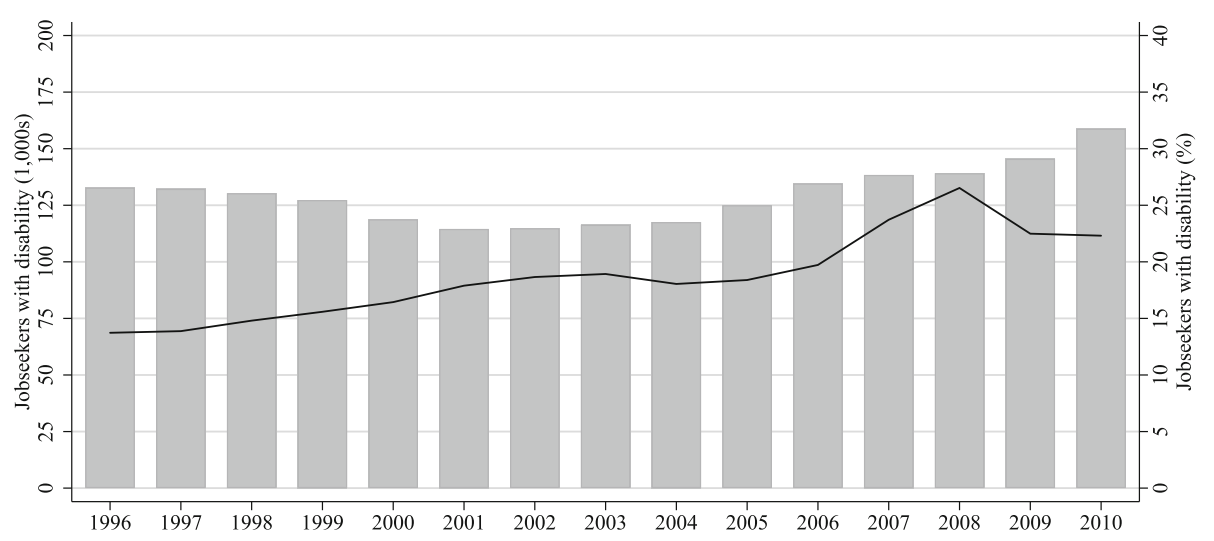

Fig. 1 The stock of jobseekers with disabilities, in 1000s (bars) and percentages (line) of all jobseekers, registered with the PES. Source: Statistics Sweden and the Swedish Public Employment Service. Own calculations

As all codes except the one for socio-medical disability are self-explanatory, no further description will be provided here. ${ }^{12} 13$

In Fig. 1, we depict the stock of jobseekers with disabilities, in numbers and as percentages of all jobseekers, during 1996-2010. After a few years of slightly diminishing numbers of jobseekers with disabilities, there was an increase from 114,000 in 2001 to 159,000 in 2010. In terms of the percentage of all jobseekers, there was instead an increase up to the Great Recession of 2008-from 13.7 to $26.5 \%$-followed by a drop in 2009 and 2010 due to the large inflow of new jobseekers. However, since the coding process described above, in many cases, takes considerable time, these figures do not provide an accurate estimate of the true number of jobseekers with an occupational disability but only the number that (at a given point in time) actually had received such a code.

\subsection{Wage subsidies targeted to jobseekers with disabilities}

The wage subsidy program (lönebidrag) was introduced in 1980 and is the single largest program among the active Swedish labour market programs. ${ }^{14}$ It is targeted only to those who have functional impairments that entail reduced work capacity and who are deemed not to be able to get or keep a job without the subsidy. ${ }^{15}$ It implies paying a wage subsidy to the employer that is supposed to compensate for the jobseekers reduced work capacity and strengthens the jobseekers' chances of getting and keeping a job. The ultimate goal is that the subsidised employment over time should turn into non-subsidised employment.

The initiative for participation in the wage subsidy program can be taken by any of the three parties (i.e. the PES, the employer, or the jobseeker), but in the end, the employer always has to apply formally. The wage subsidy amount in a particular case is determined by the PES based on both the wage cost (up to a ceiling) and the work capacity, ${ }^{16} 17 \quad 18$ while the assessment of the (reduced) work capacity includes all three parties. Following the very first decision, the granted time period for the wage subsidy is limited to 1 year, but as a general rule, an employer (either private or public) can receive the wage subsidy for a certain employee for up to 4 years. ${ }^{19}$ Under certain circumstances, the 4 -year period can be extended, but then both the granted subsidy and the corresponding amount must be reassessed on a regular basis. 


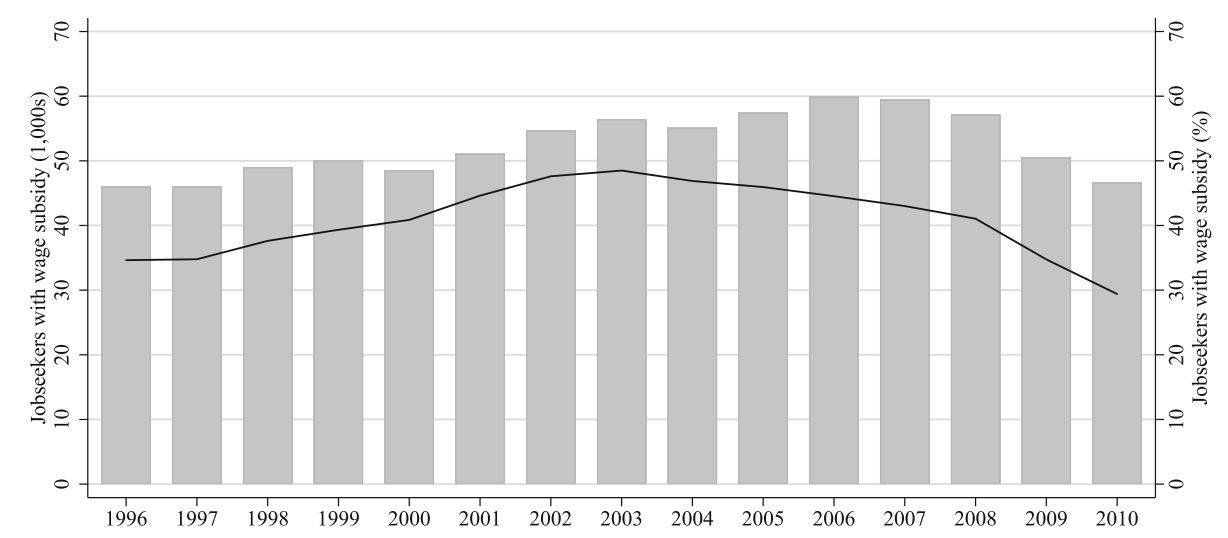

Fig. 2 The annual number of jobseekers employed with wage subsidies, in 1000s (bars) and percentages (line) of all jobseekers with disabilities. Source: Statistics Sweden and the Swedish Public Employment Service. Own calculations

Apart from being subsidised, the job should also be adapted to the jobseeker's needs and prerequisites; however, it should, in all other aspects, be viewed as regular employment. That is, it can be either part- or full-time, either be on a fixed-term or openended contract, and all terms and conditions should be in accordance with, or comparable to, the collective agreements.

In Fig. 2, we depict the annual number of jobseekers with disabilities who participated in the program during 1996-2010 (in numbers and percentages of all jobseekers with disabilities). During this period, the number of participants varied between 46,000 and 60,0000 and between 29 and $48 \%$ as a share of all jobseekers with disabilities. The figures mostly increased from 46,000 (35\%) in 1996 up to a high of 60,000 in 2006 (48\% in 2003), but then decreased by 13,000 between 2006 and 2010, despite the increasing number of jobseekers with disabilities during the same years. Hence, the share of all jobseekers with disabilities that participated in the wage subsidy program decreased to a low of $29 \%$ in 2010.

\subsection{Disability insurance}

Swedish disability insurance is administered by the Social Insurance Agency (SIA). A person can receive disability insurance if their work capacity is reduced permanently by at least $25 \% .{ }^{20}$ The benefits received are $64 \%$ of the assumed foregone earnings, up to a ceiling. Depending on the degree of lost work capacity, it is paid in quarters of the full rate. Since 1997, only medical reasons have been considered in the eligibility assessment, while, before 1997, eligibility could be granted for a combination of labour market and medical reasons. The eligibility criteria were tightened further in both 2005 and 2008.

In Fig. 3, we depict the stock of disability insurance receivers, in numbers and percentages of the working age population, during 1996-2010. During this period, the disability insurance recipients first increased monotonically, both in numbers and percentages of the working-age population, from 419,000 (7.9\%) in 2000 to 557,000 (10.0\%) in 2005. Due to the tightening of the eligibility criteria, there was a gradual decrease to $443,000(7.7 \%)$ in 2010 . 


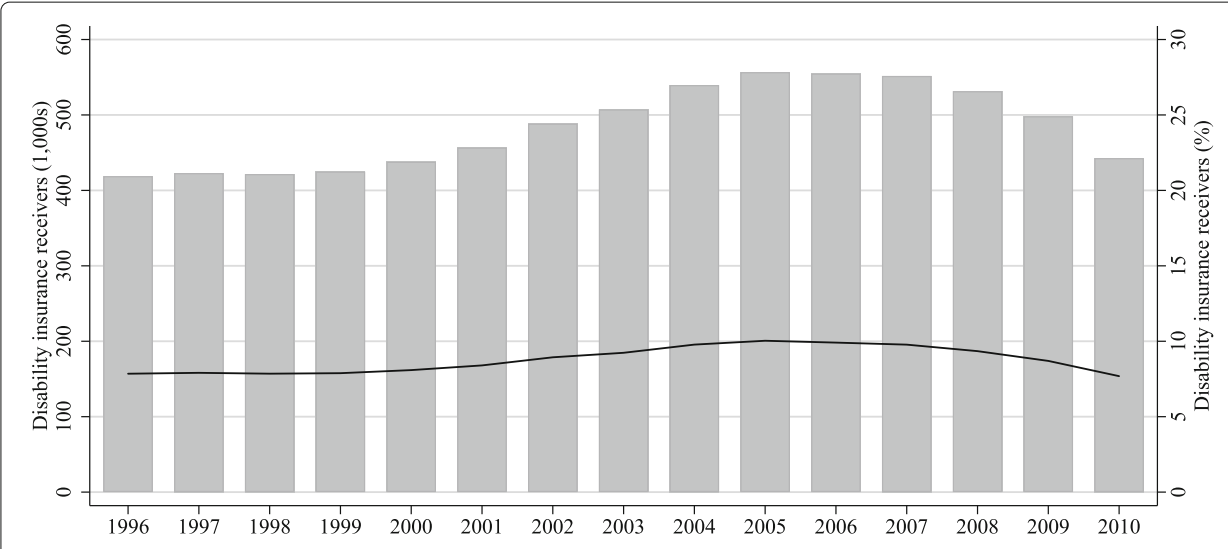

Fig. 3 The stock of disability insurance receivers, in 1000s (bars) and percentages (line) of the working-age population. Source: Statistics Sweden. Own calculations

\section{Methods}

\subsection{Data}

\subsubsection{Data sources}

The data were drawn from three administrative registers with universal coverage. First, the PES's own administrative register (HÄNDEL) was used to identify all jobseekers with occupational disabilities. It contains individual-level data on registration dates, other event dates, program participation, and occurrence and type of occupational disability. Second, from the National Patient Register, maintained by the National Board of Health and Welfare, we drew background information on hospital in-patient episodes. Third, all other background characteristics and the outcome measures (i.e. employment and disability retirement) were obtained from Statistics Sweden's longitudinal databases (LOUISE/LISA). ${ }^{21}$ The period for which the above data were available to us stretches from 1992 to 2010 .

\subsubsection{Sample selection}

To investigate the outcomes of participation in the wage subsidy program, we selected a sample comprising all who in any given quarter of year 2000: (1) had been registered as jobseekers with the PES for no more than 12 months; ${ }^{22}$ (2) were of working ages during the full study period (i.e. ages 25-54 years in 2000); (3) had been coded as occupationally disabled; (4) had not previously, during the current registration spell, participated in the wage subsidy program; and (5) either enrolled in the wage subsidy program (henceforth, the "participants") or did not (henceforth, the "non-participants"). ${ }^{23}$

This resulted in a sample comprising, on average, 685 participants and approximately 15,000 non-participants per quarter in 2000. In total, this corresponds to 2739 participants and 61,704 non-participants (whereof 2738 and 29,515 were unique individuals) (Table 1).

\subsubsection{Outcomes}

We focused on two different outcomes: employment (in the month of November) and disability retirement. ${ }^{24}$ Because non-subsidised employment is the ultimate goal of the wage subsidy program, it is an obvious outcome to study. Non-subsidised employment is not observed directly in the data but defined, instead, by using a combination of being 
Table 1 The number (and percentages) of participants and non-participants in the sample, by (potential) quarter of program enrolment

\begin{tabular}{|c|c|c|c|c|c|c|}
\hline \multirow[b]{2}{*}{ Quarter } & \multicolumn{2}{|c|}{ Participants } & \multicolumn{2}{|c|}{ Non-participants } & \multicolumn{2}{|l|}{ Total } \\
\hline & $N$ & $\%$ & $N$ & $\%$ & $N$ & $\%$ \\
\hline Q1 (Jan-Mar) & 594 & 3.48 & 16,474 & 96.52 & 17,068 & 100.00 \\
\hline Q2 (Apr-Jun) & 634 & 3.73 & 16,370 & 96.27 & 17,004 & 100.00 \\
\hline Q3 (Jul-Sep) & 644 & 4.20 & 14,695 & 95.80 & 15,339 & 100.00 \\
\hline Q4 (Oct-Dec) & 867 & 5.77 & 14,165 & 94.23 & 15,032 & 100.00 \\
\hline Q1-Q4 (Jan-Dec) & 2739 & 4.25 & 61,704 & 95.75 & 64,443 & 100.00 \\
\hline Q1-Q4 (unique obs) & 2738 & 8.49 & 29,515 & 91.51 & 32,202 & 100.00 \\
\hline
\end{tabular}

employed in the month of November and not participating in any labour market program involving wage subsidies during that month. ${ }^{25}$ Hence, as long as the participants remained in the wage subsidy program, they would by definition be counted as non-employed according to this employment measure.

In some cases, non-subsidised employment might not be a realistic goal. Therefore, we also present estimates using an alternative employment measure that does not distinguish between subsidised and non-subsidised employment (in the month of November). This measure also includes a mechanical component since participation per se is, instead, being counted as a successful employment outcome.

Given the population of interest, the transition out of the labour force through disability retirement (part- or full-time) is an equally obvious outcome to study. We define disability insurance receipt as having received a positive amount of disability insurance during the particular year. Unfortunately, we did not observe whether it was received for part- or full-time, but we did instead observe the actual annual amount received. Hence, we use this as an additional measure of disability retirement to proxy the insurance level. Importantly, eligibility for disability insurance is not related to the PES coding of occupational disability; these are two separate assessments performed by different government agencies (i.e. the PES and the SIA, respectively).

\subsubsection{Baseline characteristics and potential confounders}

The baseline characteristics that we considered as potential confounders include (1) the usual socio-demographic characteristics (i.e. sex, age, being foreign born, marital status, having children aged 0-6 and/or 7-17 years, attained educational level, county of residence), (2) measures related to the current registration spell (i.e. duration since registration with the PES, occupational disability code and duration since being coded, whether searching for a full- or part-time job, and whether searching for local jobs only), (3) 8 years of pre-program health-related measures (i.e. number of days of hospital inpatient care and the corresponding discharge diagnoses, and previously received sickness insurance and disability allowance), (4) 8 years of pre-program measures of the outcomes of interest (i.e. non-subsidised employment in November, overall employment in November, disability insurance receipt, amount of received disability insurance), and (5) 8 years of pre-program measures of other labour market outcomes (i.e. labour income, received unemployment insurance and means-tested social benefits). Summary statistics for all these baseline characteristics are presented in Appendix: Table 10. 


\subsection{Empirical strategy}

\subsubsection{The research question and choice of comparison group}

Our objective is to estimate the average difference in the outcomes of the participants in the wage subsidy program and the outcomes had they not participated (i.e. in treatment evaluation jargon, the "treatment effect on the treated" or ATET):

$$
\tau^{\mathrm{ATET}}=E\left[Y^{1}-Y^{0} \mid D=1\right]=E\left[Y^{1} \mid D=1\right]-E\left[Y^{0} \mid D=1\right]
$$

where $Y^{1}\left(Y^{0}\right)$ denotes the potential outcome if (not) participating in the wage subsidy program, and $D=1(D=0)$ indicates actual (non-)enrolment in the program. However, the fundamental problem of all labour market program evaluation is that participants cannot be simultaneously non-participants. Hence, the counterfactual outcomes had they not participated (i.e. $E\left[Y^{0} \mid D=1\right]$ ) cannot be observed. The solution is to, somehow, estimate the potential outcomes of the participants had they not participated using the outcomes of non-participants.

Before turning to the estimation of the potential outcome, we must first decide what the counterfactual situation to participation really is. Is it that they never participate or that they do not participate today but possibly later? Because the likelihood of participation in the future is positively correlated with unemployment duration, those who never participate are likely to have shorter completed unemployment durations. A static comparison of participants to "never-participants" would then imply conditioning on future outcomes (i.e. leaving unemployment), which yields inconsistent estimates (Sianesi 2004; Fredriksson and Johansson 2008). Therefore, we followed the procedure suggested in Sianesi (2004), or, to be precise, we compared those who for the first time during a registration spell enrolled in the wage subsidy program in a given quarter $(q)$ of 2000 to those who neither enrolled in the wage subsidy program during that quarter nor had participated earlier during the same registration spell (but possibly in earlier spells or later during the same spell). That is,

$$
\tau^{\operatorname{ATET}(q)}=E\left[Y^{1(q)} \mid D^{(q)}=1\right]-E\left[Y^{0(q)} \mid D^{(q)}=1\right], q=1,2,3,4
$$

Hence, each non-participant who constitutes a comparison individual in quarter $q$ will also constitute a comparison individual in each quarter $q_{+}$, such that $q<q_{+} \leq 4$, if still registered with the PES in the beginning of that quarter $\left(q_{+}\right)$. A drawback of this strategy of using a mixture of "never-participants" and "later-participants" as comparisons is that if a large share of them actually participated later on (i.e. are "later-participants"), this will tend to dilute any estimated effects of participation. ${ }^{26}$ Moreover, if we were to estimate a negative effect of program participation, we would not be able to infer whether the policy conclusion is to postpone participation or to close the program.

\subsubsection{Inverse probability weighting}

In an attempt to recover the potential outcomes of the participants had they not participated by using the outcomes of the non-participants, we have applied inverse probability (of treatment) weighting (IPW) - a standard method, together with matching, found in the toolbox of program evaluation. ${ }^{27}$ Similar to many matching estimators, IPW is based 
on reweighting using a function of the estimated propensity score (i.e. the conditional probability of program participation). ${ }^{28}$ The ATET can then be expressed as:

$$
\tau^{\mathrm{ATET}}=\frac{\sum_{i=1}^{N} D_{i} Y_{i}}{\sum_{i=1}^{N} D_{i}}-\frac{\sum_{j=1}^{N}\left(1-D_{i}\right) W_{i} Y_{i}}{\sum_{i=1}^{N}\left(1-D_{i}\right) W_{i}},
$$

where $N$ denotes the sample size, $D_{i}$ is as before an indicator of treatment (i.e. program participation), and $Y_{i}$ is the outcome of interest. Finally, $W_{i}$ is the inverse probability weight as a function of the estimated propensity score $\left(\hat{p}\left(x_{i}\right)\right)$ :

$$
W_{i}=\hat{p}\left(x_{i}\right) /\left(1-\hat{p}\left(x_{i}\right)\right),
$$

where $x_{i}$ is a vector of observed characteristics. ${ }^{29}$

\subsubsection{Duration since registration and disability coding}

An issue that we hitherto have touched upon only indirectly is the selection into the program in quarter $q$ and deregistration with the PES before quarter $q$. For example, someone who deregisters quickly as a jobseeker is not likely to be a subject for program participation, and neither is someone who has not (yet) been coded as occupationally disabled, which is a requirement for eligibility. In Section 3.2.1, we discussed how we defined the treatment effect for each (enrolment) quarter $q$ in 2000. However, in each quarter $q$, potential program participants differ in the elapsed time since registration $(r)$ and the elapsed time since being coded as occupationally disabled (c) (i.e. duration of time eligible). We believe that it is particularly important to compare participants and non-participants with the same durations $r$ and $c$. With sufficiently many participants, one could have estimated a treatment effect not only for each (enrolment) quarter $q$, but also for each combination of enrolment quarter $q$ (or even month) and durations $r$ and $c$. Given the sample size at hand, we instead chose to construct separately inverse probability weights and the corresponding treatment effect within each combination of $q, r$, and $c$ (in quarters), using the $q$-specific propensity scores $\left(p^{(q)}\right)$. However, instead of presenting 40 estimates for each outcome $Y$, we present an aggregated estimate:

$$
\tau^{\mathrm{ATET}}=\sum_{q=1}^{4} \sum_{r=1}^{4} \sum_{c \leq r} \tau_{c r}^{\operatorname{ATET}(q)}\left(N^{1} / N_{c r}^{1(q)}\right),
$$

where $N^{1}=\sum_{i=1}^{N} D_{i}$ and $N_{c r}^{1(q)}=\sum_{i=1}^{N} D_{i} I_{i}^{q} I_{i}^{c} I_{i}^{r}$ (the $I_{i}$ 's being indicator functions). ${ }^{30}$ That is, $N^{1}$ is the total number of participants enrolling in 2000, and $N_{c r}^{1(q)}$ is the number of participants enrolling in quarter $q, r$ quarters after being registered with the PES, and $c$ quarters after being coded as occupationally disabled. In practice, we will estimate Eq. 5 using weighted least squares (WLS) with cluster robust standard errors and weights

$$
\hat{W}_{i c r}^{(q)}=D_{i}+\left(1-D_{i}\right) \frac{N_{c r}^{1(q)} \frac{\hat{p}^{(q)}\left(x_{i}\right)}{1-\hat{p}^{(q)}\left(x_{i}\right)}}{\sum_{j=1}^{N}\left(1-D_{j}\right) I_{j}^{q} I_{j}^{c} I_{j}^{r} \frac{\hat{p}^{(q)}\left(x_{j}\right)}{1-\hat{p}^{(q)}\left(x_{j}\right)}} .
$$

The cluster robust standard errors account for the repeated use of (some) nonparticipants, i.e. in different (potential) enrolment quarters, but they do not account for the fact that the propensity scores are estimated. Ignoring the latter will produce conservative standard errors (Robins et al. 2000). 


\subsubsection{Assumptions}

For the IPW estimates to have a causal interpretation, four requirements have to be met. Most importantly, there should be (1) no unobserved characteristics that influence both the assignment to the wage subsidy program and the outcomes. ${ }^{31}$ This is a very strong assumption, which cannot be tested directly. In Section 4.4, we will discuss in detail its validity in the present setting and present the results from an indirect test to assess empirically its validity. (2) For all possible values of the observed characteristics $(X)$ among the participants, there are also non-participants with the same values (i.e. the overlap or common support condition): $p(X)<1$. In Section 3.2.5, we present an assessment of this condition. (3) The outcomes of one individual are not affected by the assignment of other individuals to the program (i.e. the stable unit treatment value assumption [SUTVA]). This assumption is invoked in all microeconometric evaluations of labour market programs and we cannot test its validity. Obviously, it is possible that the subsidised jobs might crowd out some unsubsidised jobs, imposing a negative bias on our estimates on non-subsidised employment. There is no reason, however, to expect that the estimates on disability retirement are affected by similar biases. (4) The propensity score model is specified correctly. This is also an untestable assumption. While it is likely to be invalid in most, if not all, observational studies, we take the view that the objective of IPW is to create a weighted pseudo-sample such that the measured confounders are balanced between the participants and non-participants; to what extent balance is achieved is assessed in Section 3.2.6.

\subsubsection{The estimated propensity scores and inverse probability weights}

In Table 2, we present summary statistics for the propensity score, which has been estimated by a sequence of four probit models (i.e. one for each quarter of 2000). From Section 3.2.4, we know that one of the conditions for the IPW to be able to provide causal estimates is that $p(X)<1$, i.e. that there are no $X$ 's that predict participation perfectly. In our data this condition is satisfied. ${ }^{32}$ It is evident that both distributions are highly skewed, with most of the mass close to zero, but that the skewness is more pronounced for the non-participants: the propensity scores lie within $[0.002,0.717]$ and $[0.000,0.718]$ for the participants and the non-participants, respectively. This implies that there is practically complete overlap in the propensity score distributions. ${ }^{33}$

An issue related to the corresponding inverse probability weights is that propensity scores close to one among the non-participants will result in very large weights that, in turn, may result in increasingly variable estimates (see, e.g. Austin and Stuart 2015). As was already evident in the previous discussion of the propensity scores, this does not pose a problem in the present setting.

Table 2 Summary statistics of the estimated propensity scores and the associated weights for the samples of participants and non-participants

\begin{tabular}{|c|c|c|c|c|c|c|c|}
\hline & \multicolumn{3}{|c|}{ Propensity score ( $p$ ) } & \multicolumn{3}{|c|}{ Inverse probability weights $(W)$} & \multirow[b]{2}{*}{$N$} \\
\hline & Mean & Min & Max & Mean & Min & Max & \\
\hline Participants $(D=1)$ & 0.104 & 0.002 & 0.717 & 1 & 1 & 1 & 2739 \\
\hline Non-participants $(D=0)$ & 0.040 & 0.000 & 0.718 & 0.045 & 0.000 & 2.468 & 61,235 \\
\hline
\end{tabular}


Table 3 Summary of the assessments of the covariate balance (absolute standardised differences in means [ASDMs] and $t$-tests of equality in means) before and after inverse probability weighting (IPW)

\begin{tabular}{|c|c|c|c|c|c|c|c|c|c|}
\hline & \multicolumn{4}{|l|}{ ASDM } & \multicolumn{4}{|c|}{$p$-value (t-test) } & \multirow[b]{2}{*}{$N^{C}$} \\
\hline & Mean & Min & $\operatorname{Max}$ & $>3^{a}$ & Mean & Min & $\operatorname{Max}$ & $<0.05^{b}$ & \\
\hline Before IPW & 13.008 & 0.019 & 52.477 & 164 & 0.089 & 0.000 & 0.992 & 158 & 198 \\
\hline After IPW & 0.516 & 0.000 & 1.763 & 0 & 0.803 & 0.377 & 1.000 & 0 & 198 \\
\hline
\end{tabular}

a Number of covariates for which ASDM $>3$.

${ }^{b}$ Number of covariates for which a $t$-test of equal means yield a $p$-value $<0.05$.

c Total number of covariates

\subsubsection{Assessment of the covariate balance}

To assess whether the IPW succeeded in balancing the observed characteristics between participants and non-participants, Appendix: Table 10 presents all covariate means together with two balance diagnostics, both before and after the IPW. For brevity, we present only a summary here (see Table 3 ).

First, before the IPW, we observe, from a $t$-test of equality of means, that 158 of the 198 covariates had means that differed significantly between participants and nonparticipants. After the IPW, we find no significant differences at all: the smallest $p$-value is 0.36 . However, since a $t$-test depends on the sample size, it does not tell us directly whether the weighted sample is, in fact, more balanced or whether the latter finding is just the consequence of a reduced (effective) sample size. Therefore, we have also computed the absolute standardised differences in means (ASDMs), defined as

$$
\operatorname{ASDM}=100 \times \frac{\left|\bar{x}_{1}-\bar{x}_{0}\right|}{\sqrt{\frac{1}{2}\left(s_{1}^{2}+s_{1}^{2}\right)}},
$$

where $\bar{x}_{1}\left(\bar{x}_{0}\right)$ and $s_{1}^{2}\left(s_{1}^{2}\right)$ denote the covariate mean and variance of the (pseudo-)sample of (non-) participants, respectively. Before IPW, the average ASDM is 13.0, and the single largest ASDM is 52.5. Out of the 198 covariates 164 had an ASDM above 3. ${ }^{34}$ This suggests, as did the $t$-test, that before IPW there was considerable covariate imbalance. ${ }^{35}$ However, it is evident that the IPW indeed improved the covariate balance significantly: the average ASDM was reduced to 0.5 and the largest value for a single covariate was reduced to 1.8. Hence, we conclude that the sample of participants and the weighted (pseudo-)sample of non-participants are very similar in terms of observed confounders. However, this does not necessarily imply that they are also similar in all of the relevant unobserved factors, an issue that we discuss further in Section 4.4.5.

\section{Results}

In this section, we present the estimates of the differences between the sample of participants in the wage subsidy program and the pseudo-sample of inverse probability weighted non-participants, with respect to employment and disability retirement outcomes. ${ }^{36}$ These estimates, with $95 \%$ confidence intervals, are presented graphically for an 8-year pre-program period and a 11-year "post-program" period (including the year of program enrollment). ${ }^{37} 38$ To shed more light on the underlying mechanisms, we also present how the average outcomes for the participants and non-participants evolved over time. 

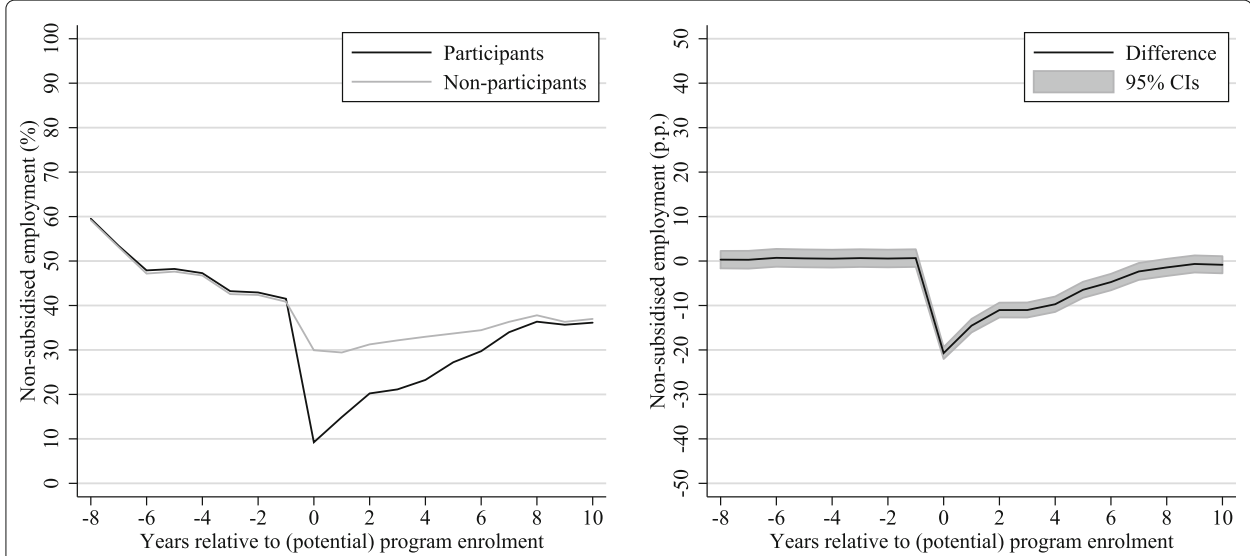

Fig. 4 Inverse probability weighted non-subsidised employment rates among participants and non-participants, respectively, and the corresponding differences with 95\% confidence intervals (95\% Cls). Notes: The non-subsidised employment rate refers to the percentage who were employed without subsidies in the month of November. Non-participants refer to those who neither participated during the same quarter nor had participated earlier during the same registration spell (but possibly in earlier spells or later during the same spell)

\subsection{Does subsidised employment turn into non-subsidised employment?}

The ultimate goal for the wage-subsidy program is regular non-subsidised employment, which makes it the most obvious outcome to study. During the eight pre-program years, the estimated differences are by construction close to zero since these measures were included in the estimation of the propensity scores. The actual employment rates are, nevertheless, interesting (see Fig. 4 [left]). Evidently, the majority among both participants and non-participants seem to have been out of (non-subsidised) work for quite some time. Eight years prior to program enrolment, the employment rate was only $59 \%$, yet it decreased further during the years that followed and was, in the year immediately preceding program enrolment, down at $41 \%$. In the year of program enrolment (and, to a lower extent, also during the following years), the participants were locked-in in subsidised employment and therefore (by definition) less likely to have a non-subsidised employment. ${ }^{39}$ Hence, it should come as no surprise that Fig. 4 (right) reveals an immediately lower likelihood of being in non-subsidised employment, as large as 19 percentage points, among the participants. During the 10 following years this difference diminished gradually to zero. These figures, however, conceal an increasing employment rate among both participants and non-participants (27 and 7 percentage points, respectively). Notably, however, the employment rates had, 10 years after (potential) program enrolment, not increased to more than $36-37 \%$.

\subsection{What should be the goal, remaining employed or becoming employed without subsidies?}

In the previous section, we showed that the participants had considerably lower nonsubsidised employment rates in the short and medium run. At least in the short run, this is likely to be a mechanical implication of that the participants, as long as they remained in the wage subsidy program, by definition are counted as non-employed. However, an arguably narrow focus on non-subsidised employment could potentially also conceal a positive effect of the wage subsidy program on long-term labour market 

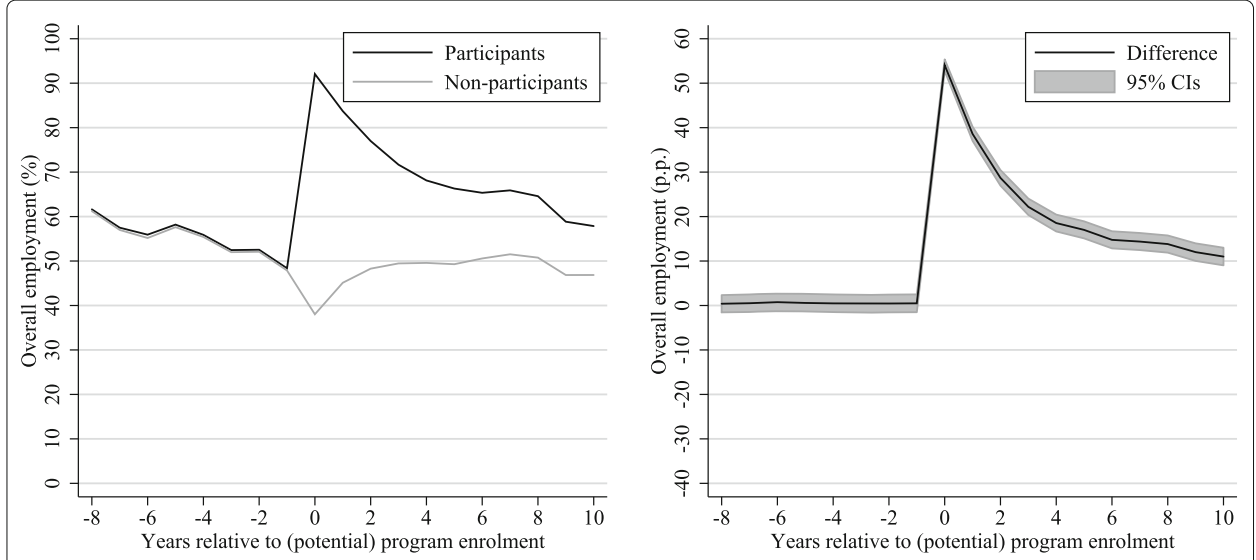

Fig. 5 Inverse probability weighted employment rates among participants and non-participants, respectively, and the corresponding differences with 95\% confidence intervals (95\% Cls). Notes: The employment rate refers to the percentage who were employed with or without subsidies in the month of November. Non-participants refer to those who neither participated during the same quarter nor had participated earlier during the same registration spell (but possibly in earlier spells or later during the same spell)

inclusion. Therefore, we present, in Fig. 5, the estimates on employment (again in the month of November) without distinguishing between subsidised and non-subsidised employment. We acknowledge, however, that these estimates to a considerable extent (especially in the shorter run) are the mechanical consequence of participation per se now being counted as a successful employment outcome.

These estimates draw a completely different picture than the one depicted in Section 4.1. During the pre-program years, the distinction between subsidised and nonsubsidised employment is not overly important (compare Figs. 4 [left] and 5 [left]). However, in the year of program enrolment there was almost full employment among the participants (i.e. 92\%). ${ }^{40}$ Hence, a gap corresponding to 54 percentage points emerged. During the years that followed, the gap closed, mostly due to participants leaving subsidised employment. However, 10 years after (potential) program enrolment, the employment rate among the participants was still as much as 11 percentage points higher than among the non-participants. Since there was no long-term difference in non-subsidised employment (cf., Fig. 4), this remaining difference is explained fully by a larger percentage of participants who still had subsidised employment. Hence, a considerable percentage of the participants seem to have either gotten the 4-year limit extended, changed employers, or jumped between different wage subsidy programs. ${ }^{41}$

\subsection{Does subsidised employment keep jobseekers with disabilities out of disability retirement?}

Disability retirement is a likely, albeit unwarranted (at least from a public policy perspective), outcome among jobseekers with occupational disabilities, especially if their work capacities are deteriorating over time. This makes it an equally obvious outcome, as was employment, to study here. However, it is not obvious how participation in the wage subsidy program should be expected to affect the likelihood of future disability retirement. On the one hand, given that disability insurance was no longer being granted for labour market reasons, but rather being determined based on the reduction in work 
capacity due to medical reasons alone, it is questionable whether one would expect program participation to have any impact at all. On the other hand, being employed (whether it be with or without a subsidy) may in itself improve a jobseeker's work capacity, while remaining unemployed may instead push the jobseeker to apply for disability insurance. This would then suggest that participation in the wage subsidy program might reduce the transition to disability insurance. Finally, a medical condition could also deteriorate if the job match is a bad one, thereby increasing the likelihood of an exit via disability retirement.

The annual percentages of participants and non-participants who received disability insurance (either part- or full-time) are depicted in Fig. 6 (left), while the corresponding differences are depicted in Fig. 6 (right). As with employment, there should be no difference in disability insurance receipt during the pre-program years. During these years, the percentages of disability insurance receivers slowly increased from 5 to $15 \%$. Following (potential) program enrolment, more participants and non-participants came to rely on disability insurance, but more so in the case of the former, and a gap of 2 percentage points emerged during the first 2 years. The percentages who received disability insurance continued to increase during the whole post-program period; 10 years after (potential) program enrolment as many as $44-46 \%$ of the participants and non-participants received disability insurance either on part- or full-time. However, the gap between the two groups closed in the second year following (potential) program enrolment and participants were somewhat less likely to rely on disability insurance during the rest of the period (by 1-3 percentage points).

As stated in Section 3.1.3, we did not observe whether disability insurance was received part- or full-time, but we did observe the actual amount received. Repeating the analysis for this measure gives a slightly different picture (compare the left graphs in Figs. 6 and 7). While both measures are increasing over time, and more so during the post-program period, the amounts received are increasing at an even faster pace than the percentages receiving any disability insurance (holds for both participants and non-participants).
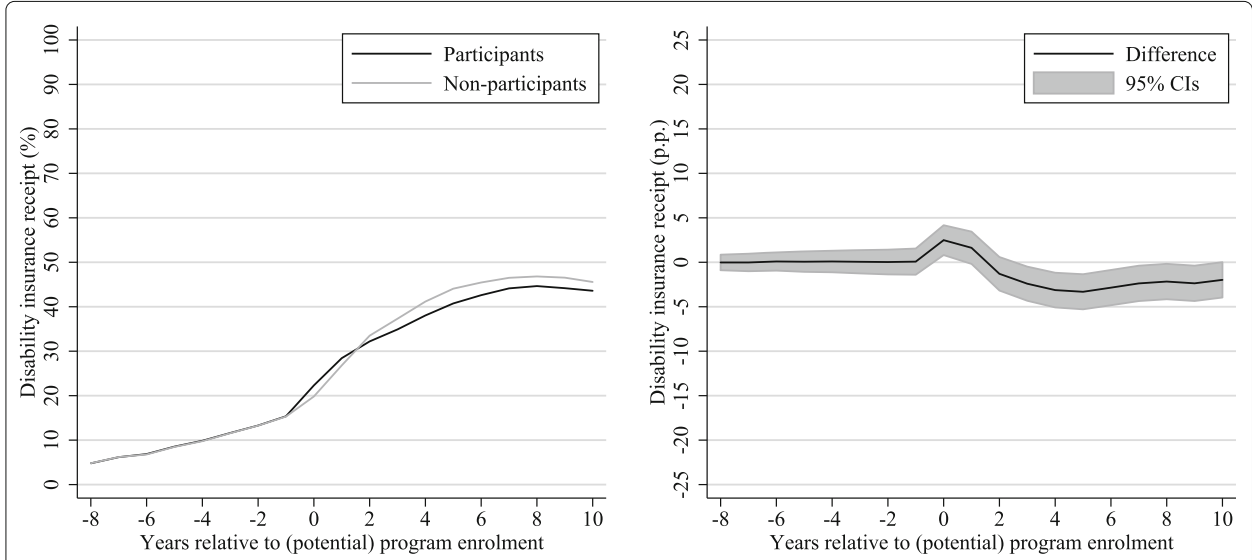

Fig. 6 Inverse probability weighted percentages of disability insurance receivers among participants and non-participants, respectively, and the corresponding differences with $95 \%$ confidence intervals ( $95 \% \mathrm{Cls}$ ) Notes: Disability insurance receivers refers to those who received any amount from disability insurance during the particular year. Non-participants refer to those who neither participated during the same quarter nor had participated earlier during the same registration spell (but possibly in earlier spells or later during the same spell) 

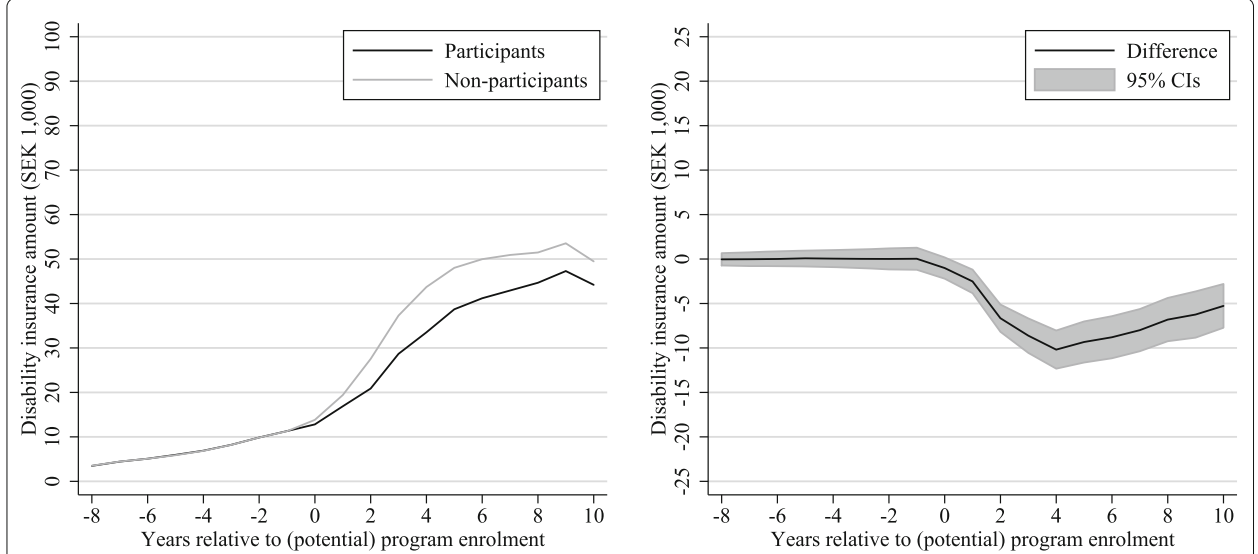

Fig. 7 Inverse probability weighted mean annual amounts of received disability insurance among participants and non-participants, respectively, and the corresponding differences with $95 \%$ confidence intervals ( $95 \% \mathrm{Cls}$ ). Notes: Non-participants refer to those who neither participated during the same quarter nor had participated earlier during the same registration spell (but possibly in earlier spells or later during the same spell). SEK $1000 \approx$ EUR 100

This suggests that not only more and more of the jobseekers came to rely on disability insurance, but that those who did also did so to a larger degree. Moreover, while the extensive margin was positively affected in the short run, the intensive margin was negatively affected (both in the short and long run), which might suggest that fewer participants came to rely entirely on disability insurance, but possible combined subsidised part-time employment and part-time disability retirement. Hence, although more than $40 \%$ entered the disability program over time, the wage subsidy program nevertheless appears to have promoted labour market inclusion by slightly reducing exits from the labour force via disability retirement.

\subsection{Sensitivity analyses}

In this section, we present the results from six additional analyses: in Sensitivity analysis I, we have changed the counterfactual case from "non-participation" to "neverparticipation"; in Sensitivity analysis II, we have ignored the timing of the disability coding; in Sensitivity analysis III, we have ignored the disability coding altogether; in Sensitivity analysis IV, we have dropped the jobseekers who were not unemployed full-time at the time of registration at the PES; in Sensitivity analysis V, both participation and nonparticipation is conditional on being employed in the month of November in the year of (potential) program enrolment; and finally in Sensitivity analysis VI, we have ignored the labour market histories earlier than the year immediately preceding the year of (potential) program enrolment. The very last analysis also serves as an indirect assessment of the validity of the unconfoundedness assumption. As far as the changes above allow, we have repeated the previous analyses using the same method and potential confounders as in Sections 4.1-4.3. ${ }^{42}$

\subsubsection{The counterfactual case}

As discussed in Section 3.2.1, how the counterfactual case is defined may affect the estimates considerably. In the main analysis, we compared participants who enrolled in a given quarter to those who had not yet participated up to, and including, that quarter. 
Here, we have instead compared the participants to "never-participants", i.e. those who at no time during the current registration spell enrolled in the wage subsidy program. On the one hand, never-participants could be regarded as a positively selected group of jobseekers, since shorter registration spells would diminish the likelihood of participation. On the other hand, jobseekers with disabilities whose work capacity was too severely reduced to make even subsidised employment a viable alternative might also be over-represented within the group of never-participants. ${ }^{43}$ Hence, it is not apparent whether constraining the comparison group to never-participants would bias the estimates upward or downward.

The results from this first sensitivity analysis are presented in Table 4. They show that in this particular setting, the change of the counterfactual case from "non-participation" to "never-participation" (i) yielded somewhat larger negative estimates on non-subsidised employment (i.e. 0-4 percentage points), (ii) increased the positive estimates on subsidised employment by 3-6 percentage points, (iii) only slightly increased the magnitude of the negative estimates on disability insurance receipt ( $<1$ percentage point), and (iv) had a rather large impact on the estimates on disability insurance amount received, i.e. up to SEK 3600 ( $\approx$ EUR 360) per year. Hence, the definition of the counterfactual case did not have any impact on any qualitative conclusions, but instead using "never-participants" as the comparison group amplified all previous quantitative findings.

Table 4 Sensitivity analysis I: Inverse probability weighted differences (Diff.), with standard errors (SE), in non-subsidised employment in the month of November, overall employment in the month of November, annual disability insurance receipt, and annual disability insurance amount received

\begin{tabular}{|c|c|c|c|c|c|c|c|c|}
\hline \multirow[b]{3}{*}{ Year } & \multicolumn{4}{|c|}{ Employment } & \multicolumn{4}{|c|}{ Disability insurance } \\
\hline & \multicolumn{2}{|c|}{ Non-subsidised } & \multicolumn{2}{|c|}{$\begin{array}{l}\text { Subsidised or } \\
\text { non-subsidised }\end{array}$} & \multicolumn{2}{|l|}{ Receipt } & \multicolumn{2}{|c|}{ Amount received } \\
\hline & Diff. & (SE) & Diff. & (SE) & Diff. & (SE) & Diff. & (SE) \\
\hline-8 & 0.006 & $(0.011)$ & 0.007 & $(0.011)$ & 0.000 & $(0.005)$ & 0.001 & $(0.383)$ \\
\hline-7 & 0.005 & $(0.011)$ & 0.008 & $(0.011)$ & 0.000 & $(0.005)$ & -0.001 & $(0.427)$ \\
\hline-6 & 0.011 & $(0.011)$ & 0.011 & $(0.011)$ & 0.001 & $(0.006)$ & 0.023 & $(0.460)$ \\
\hline-5 & 0.010 & $(0.011)$ & 0.009 & $(0.011)$ & 0.001 & $(0.006)$ & 0.106 & $(0.489)$ \\
\hline-4 & 0.008 & $(0.011)$ & 0.008 & $(0.011)$ & 0.001 & $(0.007)$ & 0.045 & $(0.527)$ \\
\hline-3 & 0.009 & $(0.011)$ & 0.006 & $(0.011)$ & 0.001 & $(0.007)$ & 0.067 & $(0.575)$ \\
\hline-2 & 0.009 & $(0.011)$ & 0.007 & $(0.011)$ & -0.001 & $(0.008)$ & 0.011 & $(0.651)$ \\
\hline-1 & 0.010 & $(0.011)$ & 0.007 & $(0.011)$ & 0.000 & $(0.008)$ & 0.017 & $(0.689)$ \\
\hline 0 & -0.225 & $(0.007)$ & 0.568 & $(0.007)$ & 0.023 & $(0.009)$ & -1.300 & $(0.683)$ \\
\hline 1 & -0.187 & $(0.008)$ & 0.447 & $(0.009)$ & 0.015 & $(0.010)$ & -3.599 & $(0.767)$ \\
\hline 2 & -0.152 & $(0.009)$ & 0.349 & $(0.010)$ & -0.017 & $(0.010)$ & -9.055 & $(0.890)$ \\
\hline 3 & -0.147 & $(0.009)$ & 0.281 & $(0.010)$ & -0.030 & $(0.011)$ & -11.575 & (1.110) \\
\hline 4 & -0.128 & $(0.010)$ & 0.237 & $(0.010)$ & -0.038 & $(0.011)$ & -13.746 & (1.215) \\
\hline 5 & -0.093 & $(0.010)$ & 0.214 & $(0.010)$ & -0.040 & $(0.011)$ & -12.839 & (1.295) \\
\hline 6 & -0.070 & $(0.010)$ & 0.190 & $(0.010)$ & -0.033 & $(0.011)$ & -12.116 & (1.323) \\
\hline 7 & -0.039 & $(0.010)$ & 0.186 & $(0.010)$ & -0.029 & $(0.011)$ & -11.064 & (1.322) \\
\hline 8 & -0.025 & $(0.011)$ & 0.181 & $(0.011)$ & -0.027 & $(0.011)$ & -9.811 & (1.350) \\
\hline 9 & -0.011 & $(0.010)$ & 0.157 & $(0.011)$ & -0.029 & $(0.011)$ & -9.129 & (1.438) \\
\hline 10 & -0.012 & $(0.010)$ & 0.146 & $(0.011)$ & -0.023 & $(0.011)$ & -7.628 & $(1.367)$ \\
\hline
\end{tabular}

Notes: In this sensitivity analysis, we have changed the counterfactual case from "non-participation" to "never-participation". Annual amounts in SEK $1000(\approx$ EUR 100) 


\subsubsection{The disability coding}

Another potentially important, and in some sense similar, issue is related to the classification of occupational disability. The ideal situation, from the researcher's point of view, would be that all jobseekers were assessed, and coded correspondingly, at the time of registration with the PES. In practice, however, the more obvious cases of occupational disabilities might be coded then, but other cases are likely to be coded much later. That this process takes time creates a bias similar to that from using never-participants as the comparison, because given a disability, the shorter the registration spell, the less likely that the jobseeker actually becomes coded as occupationally disabled. Therefore, we have investigated the sensitivity of our estimates to the coding of occupational disability by (i) ignoring at what point during the registration spell the disability was coded and (ii) ignoring the disability coding altogether.

The results from these sensitivity analyses are presented in Tables 5-6. They show, first, that ignoring the timing of disability coding did not alter any qualitative conclusions, but had a dampening impact on most estimates. Secondly, ignoring the disability coding altogether affected the results considerably: The negative estimates on non-subsidised employment were magnified by 6-11 percentage points and the positive estimates on overall employment were magnified by $1-5$ percentage points. Even more strikingly, the signs of the longer-term estimates on disability insurance receipt, and the corresponding amount received, were reversed. In the main analysis, the initially larger percentage

Table 5 Sensitivity analysis II: Inverse probability weighted differences (Diff.), with standard errors (SE), in non-subsidised employment in the month of November, overall employment in the month of November, annual disability insurance receipt, and annual disability insurance amount received

\begin{tabular}{|c|c|c|c|c|c|c|c|c|}
\hline \multirow[b]{3}{*}{ Year } & \multicolumn{4}{|c|}{ Employment } & \multicolumn{4}{|c|}{ Disability insurance } \\
\hline & \multicolumn{2}{|c|}{ Non-subsidised } & \multicolumn{2}{|c|}{$\begin{array}{l}\text { Subsidised or } \\
\text { non-subsidised }\end{array}$} & \multicolumn{2}{|l|}{ Receipt } & \multicolumn{2}{|c|}{ Amount received } \\
\hline & Diff. & (SE) & $\overline{\text { Diff. }}$ & (SE) & Diff. & (SE) & Diff. & (SE) \\
\hline-8 & 0.006 & $(0.010)$ & 0.006 & $(0.009)$ & 0.000 & $(0.004)$ & -0.001 & $(0.347)$ \\
\hline-7 & 0.006 & $(0.010)$ & 0.007 & $(0.010)$ & 0.000 & $(0.005)$ & 0.004 & $(0.393)$ \\
\hline-6 & 0.008 & $(0.010)$ & 0.008 & $(0.010)$ & 0.001 & $(0.005)$ & 0.017 & $(0.422)$ \\
\hline-5 & 0.007 & $(0.010)$ & 0.007 & $(0.010)$ & 0.001 & $(0.006)$ & 0.040 & $(0.447)$ \\
\hline-4 & 0.007 & $(0.010)$ & 0.006 & $(0.010)$ & 0.001 & $(0.006)$ & 0.033 & $(0.479)$ \\
\hline-3 & 0.007 & $(0.010)$ & 0.005 & $(0.010)$ & 0.001 & $(0.006)$ & 0.003 & $(0.524)$ \\
\hline-2 & 0.005 & $(0.010)$ & 0.003 & $(0.010)$ & 0.001 & $(0.007)$ & 0.033 & $(0.585)$ \\
\hline-1 & 0.005 & $(0.010)$ & 0.003 & $(0.010)$ & 0.001 & $(0.007)$ & 0.059 & $(0.614)$ \\
\hline 0 & -0.199 & $(0.006)$ & 0.553 & $(0.006)$ & 0.030 & $(0.008)$ & -0.729 & $(0.579)$ \\
\hline 1 & -0.112 & $(0.007)$ & 0.415 & (0.008) & 0.030 & $(0.009)$ & -1.476 & $(0.635)$ \\
\hline 2 & -0.080 & $(0.008)$ & 0.305 & $(0.008)$ & 0.003 & $(0.009)$ & -4.887 & $(0.738)$ \\
\hline 3 & -0.080 & $(0.008)$ & 0.237 & $(0.009)$ & -0.011 & $(0.009)$ & -6.646 & $(0.941)$ \\
\hline 4 & -0.069 & $(0.008)$ & 0.193 & $(0.009)$ & -0.019 & $(0.010)$ & -8.385 & (1.040) \\
\hline 5 & -0.041 & (0.009) & 0.171 & $(0.009)$ & -0.024 & $(0.010)$ & -7.850 & (1.125) \\
\hline 6 & -0.027 & $(0.009)$ & 0.148 & (0.009) & -0.022 & $(0.010)$ & -7.601 & (1.158) \\
\hline 7 & -0.007 & $(0.009)$ & 0.143 & (0.009) & -0.019 & $(0.010)$ & -6.959 & (1.159) \\
\hline 8 & 0.001 & (0.009) & 0.141 & (0.009) & -0.019 & $(0.010)$ & -5.831 & (1.192) \\
\hline 9 & 0.009 & (0.009) & 0.122 & $(0.010)$ & -0.020 & $(0.010)$ & -5.182 & $(1.273)$ \\
\hline 10 & 0.004 & (0.009) & 0.111 & $(0.010)$ & -0.016 & $(0.010)$ & -4.051 & $(1.210)$ \\
\hline
\end{tabular}

Notes: In this sensitivity analysis, we have ignored the timing of the disability coding. Annual amounts in SEK $1000(\approx$ EUR 100) 
Table 6 Sensitivity analysis III: Inverse probability weighted differences (Diff.), with standard errors (SE), in non-subsidised employment in the month of November, overall employment in the month of November, annual disability insurance receipt, and annual disability insurance amount received

\begin{tabular}{|c|c|c|c|c|c|c|c|c|}
\hline \multirow[b]{3}{*}{ Year } & \multicolumn{4}{|c|}{ Employment } & \multicolumn{4}{|c|}{ Disability insurance } \\
\hline & \multicolumn{2}{|c|}{ Non-subsidised } & \multicolumn{2}{|c|}{$\begin{array}{l}\text { Subsidised or } \\
\text { non-subsidised }\end{array}$} & \multicolumn{2}{|l|}{ Receipt } & \multicolumn{2}{|c|}{ Amount received } \\
\hline & Diff. & (SE) & Diff. & (SE) & Diff. & (SE) & Diff. & (SE) \\
\hline-8 & 0.012 & (0.009) & 0.011 & (0.009) & -0.004 & $(0.004)$ & -0.276 & $(0.334)$ \\
\hline-7 & 0.013 & $(0.009)$ & 0.011 & $(0.009)$ & -0.005 & $(0.005)$ & -0.350 & $(0.379)$ \\
\hline-6 & 0.020 & $(0.009)$ & 0.011 & $(0.009)$ & -0.005 & $(0.005)$ & -0.390 & $(0.409)$ \\
\hline-5 & 0.021 & $(0.009)$ & 0.011 & $(0.009)$ & -0.007 & $(0.006)$ & -0.409 & $(0.435)$ \\
\hline-4 & 0.021 & $(0.009)$ & 0.010 & $(0.009)$ & -0.007 & $(0.006)$ & -0.484 & $(0.464)$ \\
\hline-3 & 0.023 & $(0.009)$ & 0.011 & $(0.009)$ & -0.009 & $(0.006)$ & -0.606 & $(0.508)$ \\
\hline-2 & 0.020 & $(0.009)$ & 0.010 & $(0.009)$ & -0.010 & $(0.007)$ & -0.685 & $(0.567)$ \\
\hline-1 & 0.019 & $(0.009)$ & 0.012 & $(0.010)$ & -0.011 & $(0.007)$ & -0.733 & $(0.597)$ \\
\hline 0 & -0.295 & $(0.006)$ & 0.487 & $(0.006)$ & 0.022 & $(0.008)$ & -1.668 & $(0.568)$ \\
\hline 1 & -0.251 & $(0.007)$ & 0.353 & $(0.007)$ & 0.036 & (0.009) & -1.992 & $(0.622)$ \\
\hline 2 & -0.215 & (0.008) & 0.262 & $(0.008)$ & 0.031 & $(0.009)$ & -4.106 & $(0.725)$ \\
\hline 3 & -0.199 & $(0.008)$ & 0.209 & (0.009) & 0.032 & (0.009) & -3.992 & $(0.926)$ \\
\hline 4 & -0.187 & $(0.008)$ & 0.164 & $(0.009)$ & 0.038 & (0.009) & -3.757 & $(1.016)$ \\
\hline 5 & -0.150 & (0.009) & 0.144 & $(0.009)$ & 0.044 & $(0.009)$ & -1.930 & (1.098) \\
\hline 6 & -0.132 & $(0.009)$ & 0.123 & $(0.009)$ & 0.050 & (0.009) & -1.109 & $(1.127)$ \\
\hline 7 & -0.107 & $(0.009)$ & 0.119 & $(0.009)$ & 0.056 & $(0.010)$ & -0.227 & (1.128) \\
\hline 8 & -0.087 & (0.009) & 0.116 & (0.009) & 0.057 & $(0.010)$ & 0.830 & (1.159) \\
\hline 9 & -0.073 & (0.009) & 0.092 & (0.009) & 0.056 & $(0.009)$ & 1.791 & $(1.235)$ \\
\hline 10 & -0.072 & $(0.009)$ & 0.084 & $(0.009)$ & 0.060 & (0.009) & 2.544 & $(1.176)$ \\
\hline
\end{tabular}

of disability insurance receivers among the participants quickly reverted and became lower from the third year following participation onward. When the disability coding was ignored altogether, an initially similar gap instead continued to widen to 6 percentage points 10 years following (potential) program enrolment. Although being coded as occupationally disabled by the PES does not automatically make one eligible for disability insurance, it is not farfetched to assume that the code nevertheless is indicative of a functional impairment that at least over time will increase the likelihood of becoming eligible. Hence, although the finding of a difference in disability retirement of the opposite sign when ignoring the jobseekers' disability codes is striking, it is not necessarily surprising.

\subsubsection{All jobseekers or only full-time unemployed jobseekers?}

In the main analysis, we included all those who registered at the PES as job seekers and who were coded as occupationally disabled. That is, we did not distinguish between jobseekers who were unemployed full-time and those who, for example, were job-changers or unemployed part-time. About half of the jobseekers were full-time unemployed at the time of registration at the PES, and in this sensitivity analysis, we dropped those who were not.

The results from this analysis are presented in Table 7. These estimates are very close to our main results. Hence, we conclude that whether the jobseekers are constrained to those who were unemployed full-time at the time of registration with the PES or if we include also all other jobseekers has no impact on our results. 
Table 7 Sensitivity analysis IV: Inverse probability weighted differences (Diff.), with standard errors (SE), in non-subsidised employment in the month of November, overall employment in the month of November, annual disability insurance receipt, and annual disability insurance amount received

\begin{tabular}{|c|c|c|c|c|c|c|c|c|}
\hline \multirow[b]{3}{*}{ Year } & \multicolumn{4}{|c|}{ Employment } & \multicolumn{4}{|c|}{ Disability insurance } \\
\hline & \multicolumn{2}{|c|}{ Non-subsidised } & \multicolumn{2}{|c|}{$\begin{array}{l}\text { Subsidised or } \\
\text { non-subsidised }\end{array}$} & \multicolumn{2}{|l|}{ Receipt } & \multicolumn{2}{|c|}{ Amount received } \\
\hline & Diff. & (SE) & $\overline{\text { Diff. }}$ & (SE) & $\overline{\text { Diff. }}$ & (SE) & Diff. & (SE) \\
\hline-8 & 0.004 & $(0.015)$ & 0.005 & $(0.015)$ & -0.001 & $(0.006)$ & -0.117 & $(0.477)$ \\
\hline-7 & 0.003 & $(0.015)$ & 0.003 & $(0.015)$ & -0.002 & $(0.007)$ & -0.122 & $(0.511)$ \\
\hline-6 & 0.004 & $(0.015)$ & 0.005 & $(0.015)$ & -0.001 & $(0.007)$ & -0.176 & $(0.558)$ \\
\hline-5 & 0.002 & $(0.015)$ & 0.004 & $(0.015)$ & 0.000 & $(0.008)$ & -0.074 & $(0.633)$ \\
\hline-4 & 0.003 & $(0.015)$ & 0.003 & $(0.015)$ & -0.001 & $(0.008)$ & -0.165 & $(0.674)$ \\
\hline-3 & 0.005 & $(0.014)$ & 0.002 & $(0.015)$ & -0.003 & $(0.009)$ & -0.322 & $(0.786)$ \\
\hline-2 & 0.004 & $(0.014)$ & 0.001 & $(0.015)$ & -0.002 & $(0.010)$ & -0.165 & $(0.870)$ \\
\hline-1 & 0.003 & $(0.014)$ & 0.003 & $(0.014)$ & 0.000 & $(0.010)$ & -0.075 & $(0.904)$ \\
\hline 0 & -0.150 & $(0.009)$ & 0.603 & $(0.010)$ & 0.027 & $(0.012)$ & -0.581 & $(0.850)$ \\
\hline 1 & -0.116 & $(0.011)$ & 0.394 & $(0.013)$ & 0.019 & $(0.013)$ & -1.959 & $(0.945)$ \\
\hline 2 & -0.099 & $(0.012)$ & 0.269 & $(0.014)$ & -0.007 & $(0.014)$ & -4.796 & (1.123) \\
\hline 3 & -0.086 & $(0.012)$ & 0.213 & $(0.014)$ & -0.021 & $(0.014)$ & -7.334 & $(1.381)$ \\
\hline 4 & -0.082 & $(0.013)$ & 0.171 & $(0.015)$ & -0.024 & $(0.014)$ & -8.860 & (1.529) \\
\hline 5 & -0.056 & $(0.013)$ & 0.152 & $(0.015)$ & -0.029 & $(0.014)$ & -7.948 & (1.646) \\
\hline 6 & -0.029 & $(0.014)$ & 0.137 & $(0.015)$ & -0.025 & $(0.015)$ & -8.025 & (1.677) \\
\hline 7 & -0.001 & $(0.014)$ & 0.143 & $(0.015)$ & -0.024 & $(0.015)$ & -7.567 & (1.694) \\
\hline 8 & 0.014 & $(0.014)$ & 0.146 & $(0.015)$ & -0.027 & $(0.015)$ & -6.975 & (1.745) \\
\hline 9 & 0.003 & $(0.014)$ & 0.116 & $(0.015)$ & -0.030 & $(0.015)$ & -7.047 & (1.857) \\
\hline 10 & 0.004 & $(0.014)$ & 0.107 & (0.015) & -0.028 & $(0.015)$ & -5.610 & (1.758) \\
\hline
\end{tabular}

Notes: In this sensitivity analysis, we have dropped jobseekers who were not full-time unemployed at the time of registration at the PES. Annual amounts in SEK 1000 ( $\approx$ EUR 100)

\subsubsection{The wage subsidy as a "double treatment"}

In Section 1, we mentioned that Jaenichen and Stephan (2011) referred to wage subsidies as the "double treatment" of (i) getting a job and (ii) receiving a subsidy. In an attempt to isolate the effect of the subsidy, they provided estimates conditional on taking up a job. Here, we provide the results from a similar analysis. We have constrained our sample of non-participants to those who had non-subsidised employment in the month of November in the year of (potential) program enrolment. ${ }^{44}$ To similarly define our sample of participants, we constrained it to those who had subsidised employment in the month of November in the year of (potential) program enrolment. ${ }^{45}$

The results from this sensitivity analysis are presented in Table 8 . In the very short run, constraining the sample of non-participants to those who had non-subsidised employment in the month of November of the year of (potential) program enrolment, has large mechanical effects. In the year of (potential) program enrolment, the difference between participants and non-participants in terms of non-subsidised employment is by construction 100 percentage points. Also by construction, there is no difference between participants and non-participants in terms of overall employment. More interesting is therefore how the longer run estimates are affected. Regarding non-subsidised employment, the participants do not seem to really catch up. In the end of the follow-up period, there was a remaining employment gap of 13 percentage points, which should be compared to the 1 percentage point from the main analysis. 
Table 8 Sensitivity analysis V: Inverse probability weighted differences (Diff.), with standard errors (SE), in non-subsidised employment in the month of November, overall employment in the month of November, annual disability insurance receipt, and annual disability insurance amount received

\begin{tabular}{|c|c|c|c|c|c|c|c|c|}
\hline \multirow[b]{3}{*}{ Year } & \multicolumn{4}{|c|}{ Employment } & \multicolumn{4}{|c|}{ Disability insurance } \\
\hline & \multicolumn{2}{|c|}{ Non-subsidised } & \multicolumn{2}{|c|}{$\begin{array}{l}\text { Subsidised or } \\
\text { non-subsidised }\end{array}$} & \multicolumn{2}{|c|}{ Receipt } & \multicolumn{2}{|c|}{ Amount received } \\
\hline & $\overline{\text { Diff. }}$ & (SE) & $\overline{\text { Diff. }}$ & (SE) & $\overline{\text { Diff. }}$ & (SE) & Diff. & (SE) \\
\hline-8 & -0.001 & $(0.016)$ & 0.002 & $(0.016)$ & 0.002 & $(0.008)$ & 0.156 & $(0.638)$ \\
\hline-7 & 0.009 & $(0.016)$ & 0.013 & $(0.016)$ & 0.006 & $(0.009)$ & 0.252 & $(0.721)$ \\
\hline-6 & 0.012 & $(0.016)$ & 0.017 & $(0.016)$ & 0.007 & $(0.009)$ & 0.394 & $(0.746)$ \\
\hline-5 & 0.006 & $(0.016)$ & 0.012 & $(0.016)$ & 0.008 & $(0.010)$ & 0.630 & $(0.793)$ \\
\hline-4 & 0.007 & $(0.016)$ & 0.008 & $(0.016)$ & 0.008 & $(0.011)$ & 0.481 & $(0.930)$ \\
\hline-3 & 0.004 & $(0.016)$ & 0.005 & $(0.016)$ & 0.000 & $(0.014)$ & 0.232 & $(1.080)$ \\
\hline-2 & -0.008 & $(0.016)$ & -0.009 & $(0.016)$ & 0.000 & $(0.015)$ & -0.221 & (1.469) \\
\hline-1 & 0.003 & $(0.015)$ & -0.002 & $(0.016)$ & 0.003 & $(0.015)$ & 0.221 & $(1.475)$ \\
\hline 0 & -1.000 & N/A & 0.000 & N/A & 0.040 & $(0.016)$ & 1.399 & (1.403) \\
\hline 1 & -0.482 & (0.015) & 0.162 & $(0.014)$ & 0.061 & $(0.017)$ & 1.741 & (1.493) \\
\hline 2 & -0.375 & (0.015) & 0.121 & $(0.015)$ & 0.042 & $(0.017)$ & -0.606 & (1.557) \\
\hline 3 & -0.337 & $(0.015)$ & 0.067 & $(0.016)$ & 0.044 & $(0.017)$ & -0.844 & (1.767) \\
\hline 4 & -0.309 & $(0.015)$ & 0.036 & $(0.015)$ & 0.042 & $(0.017)$ & -1.784 & (1.885) \\
\hline 5 & -0.250 & $(0.016)$ & 0.039 & $(0.015)$ & 0.041 & $(0.017)$ & -0.142 & (1.974) \\
\hline 6 & -0.220 & $(0.016)$ & 0.028 & $(0.016)$ & 0.047 & $(0.017)$ & 0.433 & (2.005) \\
\hline 7 & -0.175 & $(0.016)$ & 0.038 & $(0.016)$ & 0.048 & $(0.017)$ & 1.543 & (1.984) \\
\hline 8 & -0.156 & $(0.016)$ & 0.037 & $(0.016)$ & 0.052 & $(0.017)$ & 2.322 & (2.004) \\
\hline 9 & -0.122 & $(0.016)$ & 0.040 & $(0.016)$ & 0.052 & $(0.017)$ & 2.910 & (2.171) \\
\hline 10 & -0.129 & $(0.016)$ & 0.026 & $(0.016)$ & 0.055 & $(0.017)$ & 3.564 & (2.053) \\
\hline
\end{tabular}

Notes: In this sensitivity analysis, participation and non-participation are conditional on being employed in the month of November in the year of (potential) program enrolment. Annual amounts in SEK 1000 ( $\approx$ EUR 100)

In the main analysis, the participants had a much larger overall employment rateespecially in the short run, but also in the longer run-than the non-participants. The estimates in this subsection show that overall employment was higher among participants also when compared to non-participants who obtained a job without a subsidy: a gap of 16 percentage points in the year following (potential) participation, which 3 years later had decreased to a lasting (marginally statistically significant) difference of about 4 percentage points. This would, in terms of the "double treatment" referred to in Jaenichen and Stephan (2011), suggest that the positive difference found in the main analysis is not explained fully by that the participants by definition became employed, but rather the subsidy per se also seems to have positively affected job stability (which in more negative terms could be referred to as a "locking-in effect").

Furthermore, the previous negative estimates, in the medium to long run, on disability retirement are reversed when comparing the participants to non-participants who also took up employment, but without any subsidies. This might suggest that it is more common to combine subsidised, than non-subsidised, employment with part-time disability retirement.

Finally, it can be questioned whether our main results can be interpreted as causal effects of participation in the wage subsidy program or if they are merely the result of the two groups differing in factors that we cannot observe, which is discussed further in Section 4.4.5. Such a factor could, for example, be the work capacity (or the extent to which the same is reduced by the impairment). All participants are likely to have a higher 
work capacity than many (but not all) other jobseekers with disabilities, since they all were, in fact, able to obtain a job (albeit with a subsidy). However, the comparisons in the present sensitivity analysis are likely to be even more positively selected, since they all were able to obtain a job even without the subsidy. We therefore interpret the estimates using this comparison group as a lower (upper) bound of the "true" estimate of the total effect of the wage subsidy program on non-subsidised employment (disability retirement).

\subsubsection{Similar or only observably similar?}

Whether our results have a causal interpretation hinges on whether we have been able to balance all (observed and unobserved) characteristics that are jointly correlated with program assignment and the outcomes (i.e. whether the unconfoundedness assumption is valid). One could argue that because we observe not only the usual socio-demographic characteristics but also the type of occupational disability and 8 years of pre-program labour market history (including the outcomes under study), hospital in-patient history, and sickness absence history, not much relevant information is left unobserved. Both Lechner and Wunsch (2013) and Caliendo et al. (2017) also concluded-in their analyses of the sensitivity of labour market program evaluations to the inclusion of information that is usually unobserved by the researcher-that the detailed information available in rich European administrative data, including labour market histories, removes most of the selection bias. However, as also noted in Caliendo et al. (2017), the selection to subsidised employment might be more complex than that to other active labour market programs because there must be an employer willing to hire the jobseeker (with the wage subsidy).

Moreover, given the focus on jobseekers with disabilities, the lack of any observed measure of work capacity at the time of assignment, and how it is expected to evolve over time, might be increasingly important. Although we observe the 11 occupational disability codes given by the PES, each code/category naturally contains a spectrum of impairments of varying severity that also will affect work capacity to varying degrees. Work capacity, or the lack of the same, is obviously strongly associated with our outcomes. It is also intricately related to the assignment to the wage subsidy program in a number of ways. First, the eligibility criteria does not only state that the jobseekers should have been deemed to have an occupational disability and a reduced work capacity, but also that they should not be able to get or keep a job without the wage subsidy (see Government Ordinance 2000:630). Second, there are other programs targeted to jobseekers with occupational disabilities (e.g. sheltered employment) that are reserved for those whose work capacity is sufficiently reduced to hinder them from obtaining any other (non-subsidised or subsidised) employment. Together, these two statements imply that those assigned to the wage subsidy program are likely to be drawn from the middle part of the distribution of work capacity and not from either tail. Moreover, as has already been mentioned above, although assignments are ruled by the PES's caseworkers, there needs to be also an employer willing to hire each particular jobseeker. It is not obvious that the employer would necessarily prefer a jobseeker with a less reduced work capacity, as the wage subsidy is supposed to compensate for it regardless of its level, but some positive selection on the basis of the jobseeker's characteristics, observed or unobserved, is likely. We conclude that the assignment to the wage subsidy program is likely based partly on characteristics not observed to us. One could, nevertheless, argue again that the 8-year pre-program 
measures of, in particular, the outcomes might serve as proxies for these unobserved characteristics.

That we have access to these pre-program measures of the outcomes does not only make the unconfoundedness assumption more plausible, but it also allows us to test its plausibility indirectly. As suggested in Heckman and Hotz (1989) and discussed in Imbens and Wooldridge (2009), one can test the unconfoundedness assumption indirectly by estimating the effect on a pre-program measure of the outcome conditioning on all, or a subset of, the other pre-program measures of that outcome. For example, one could condition on the most recent measure $\left(Y_{t-1}\right)$ and the other characteristics and estimate the effect on the more distant measures $\left(Y_{t-8}, Y_{t-7}, \ldots, Y_{t-2}\right)$. Because these measures cannot have been affected by program participation, a non-zero estimate indicates that the participants and non-participants are not comparable (i.e. that the unconfoundedness assumption is not valid); at least not conditional only on the most recent measures of the outcomes $\left(Y_{t-1}\right)$. If it instead is zero, it does not imply directly that the assumption is valid, but Imbens and Wooldridge (2009) argue that the test, nevertheless, can be used to "plausibly assess unconfoundedness".

We have performed such a test for each of the four outcomes (see Table 9). We found that conditioning on the measures closest to (potential) program enrolment (i.e. the $Y_{t-1}$ 's) is sufficient to make the differences in all of the more distant measures (i.e. in $t-8$

Table 9 Sensitivity analysis VI: Inverse probability weighted differences (Diff.), with standard errors (SE), in non-subsidised employment in the month of November, overall employment in the month of November, annual disability insurance receipt, and annual disability insurance amount received

\begin{tabular}{|c|c|c|c|c|c|c|c|c|}
\hline \multirow[b]{3}{*}{ Year } & \multicolumn{4}{|c|}{ Employment } & \multicolumn{4}{|c|}{ Disability insurance } \\
\hline & \multicolumn{2}{|c|}{ Non-subsidised } & \multicolumn{2}{|c|}{$\begin{array}{l}\text { Subsidised or } \\
\text { non-subsidised }\end{array}$} & \multicolumn{2}{|l|}{ Receipt } & \multicolumn{2}{|c|}{ Amount received } \\
\hline & Diff. & (SE) & Diff. & (SE) & Diff. & (SE) & Diff. & (SE) \\
\hline-8 & 0.022 & $(0.010)$ & 0.017 & $(0.010)$ & 0.004 & $(0.004)$ & 0.359 & $(0.341)$ \\
\hline-7 & 0.021 & $(0.010)$ & 0.026 & $(0.010)$ & 0.006 & $(0.005)$ & 0.493 & $(0.380)$ \\
\hline-6 & 0.026 & $(0.010)$ & 0.039 & $(0.010)$ & 0.000 & $(0.005)$ & 0.017 & $(0.421)$ \\
\hline-5 & 0.033 & $(0.010)$ & 0.052 & $(0.010)$ & 0.002 & $(0.006)$ & 0.000 & $(0.453)$ \\
\hline-4 & 0.026 & $(0.010)$ & 0.047 & $(0.010)$ & 0.001 & $(0.006)$ & 0.082 & $(0.477)$ \\
\hline-3 & 0.018 & $(0.010)$ & 0.039 & $(0.010)$ & 0.004 & $(0.007)$ & 0.162 & $(0.526)$ \\
\hline-2 & 0.009 & $(0.010)$ & 0.022 & $(0.010)$ & 0.000 & $(0.007)$ & 0.257 & $(0.584)$ \\
\hline-1 & 0.006 & $(0.010)$ & 0.005 & $(0.010)$ & 0.000 & $(0.007)$ & -0.041 & $(0.622)$ \\
\hline 0 & -0.207 & $(0.007)$ & 0.541 & $(0.007)$ & 0.025 & $(0.008)$ & -1.026 & $(0.593)$ \\
\hline 1 & -0.145 & $(0.008)$ & 0.387 & $(0.008)$ & 0.018 & $(0.009)$ & -2.429 & $(0.657)$ \\
\hline 2 & -0.111 & $(0.008)$ & 0.289 & $(0.009)$ & -0.011 & $(0.010)$ & -6.479 & $(0.766)$ \\
\hline 3 & -0.108 & (0.009) & 0.228 & $(0.009)$ & -0.022 & $(0.010)$ & -8.270 & $(0.972)$ \\
\hline 4 & -0.092 & $(0.009)$ & 0.193 & $(0.010)$ & -0.031 & $(0.010)$ & -9.913 & $(1.076)$ \\
\hline 5 & -0.061 & (0.009) & 0.176 & $(0.010)$ & -0.034 & $(0.010)$ & -9.296 & $(1.164)$ \\
\hline 6 & -0.042 & (0.009) & 0.157 & $(0.010)$ & -0.030 & $(0.010)$ & -8.832 & $(1.192)$ \\
\hline 7 & -0.017 & $(0.010)$ & 0.152 & $(0.010)$ & -0.025 & $(0.010)$ & -8.018 & (1.195) \\
\hline 8 & -0.008 & $(0.010)$ & 0.148 & $(0.010)$ & -0.023 & $(0.010)$ & -6.823 & $(1.226)$ \\
\hline 9 & 0.002 & $(0.010)$ & 0.130 & $(0.010)$ & -0.025 & $(0.010)$ & -6.210 & $(1.310)$ \\
\hline 10 & -0.001 & $(0.010)$ & 0.118 & $(0.010)$ & -0.021 & $(0.010)$ & -5.276 & $(1.239)$ \\
\hline
\end{tabular}

Notes: In this sensitivity analysis, we have ignored the labour market histories earlier than the year immediately preceding the year of (potential) program enrolment. Annual amounts in SEK 1000 ( $\approx$ EUR 100) 
to $t-2$ ) of the two disability retirement outcomes, between the participants and nonparticipants, statistically indistinguishable from zero. ${ }^{46}$ However, for the more distant measures of the two employment outcomes, only 3 out of 14 were balanced between the two groups.

A conclusion based on the disability retirement outcomes alone might then be that it is plausible that the unconfoundedness assumption is valid, but the findings for the employment outcomes obviously question this conclusion. Noteworthy, however, is that conditioning only on the most recent of the lagged measures had virtually no impact at all on the post-program estimates.

\section{Conclusions}

About one out of ten in the working-age population has some kind of impairment that entails reduced work capacity. Yet the empirical evidence on the effectiveness of policies aimed at enhancing labour market inclusion among people with disabilities, such as targeted wage subsidies, is scarce in the economics literature. In an attempt to shed some light on this issue, we have studied how the labour market outcomes, in terms of employment and disability retirement, of jobseekers with disabilities are affected by participation in a wage subsidy program.

We found that the participants in the program had a much larger subsequent overall employment rate (with or without subsidies) than observably similar non-participants. Much of the large initial difference is obviously a mechanical consequence of the program participation per se being counted as a positive outcome (i.e. subsidised employment), but an 11 percentage point difference remained after 10 years. If subsidised jobs are excluded from the employment measure, the picture changes dramatically. Given that the wage subsidy can be granted for 4 years, and under certain circumstances even longer, one would at least in the short and medium run expect considerable locking-in effects, which is also what we found.

An emerging question is how to interpret these findings. On the one hand, a pessimistic view would be that there were substantial "locking-in" effects of participation in the wage subsidy program that reduced the transition to non-subsidised employment. On the other hand, a more optimistic view would be that these individuals would not have been able to keep a job without the subsidy (neither in the short nor in the longer run) and that the subsidy therefore enhanced labour market inclusion. As the percentage of disability insurance receivers among the participants is somewhat lower than among the non-participants, we find some support for the latter.

Our findings differ greatly from those reported in Jaenichen and Stephan (2011) on the effectiveness of wage subsidies targeted to "hard-to-place" workers (including, among others, workers with disabilities) in Germany. While they too found locking-in effects of the wage subsidy program, they found large positive-not negative-effects on nonsubsidised employment following the expiration of the subsidy (i.e. after 7-12 months). They referred to this effect as the combined effect of receiving the wage subsidy and getting a job, and, in an attempt to isolate the effect of the wage subsidy (net of the effect of getting a job), they also provided estimates conditional on taking-up a (subsidised or non-subsidised) job. Necessarily, doing so largely amplified the initial (and mechanical) locking-in effect and dampened considerably the positive effect on nonsubsidised employment. We found that such an analysis affected our estimates on 
employment in the same directions: it dampened greatly the positive effect on overall (subsidised or non-subsidised) employment and amplified greatly the negative estimates on non-subsidised employment.

However, conditioning on taking-up a (subsidised or non-subsidised) job implies that the comparison group comprises jobseekers who, despite that they were classified as occupationally disabled, had a work capacity that was not sufficiently reduced to hinder them from getting a job, even without subsidies. This is certainly a positively selected group of jobseekers with disabilities, which, unless accounted for by our empirical analysis, will bias our estimates. In terms of disability retirement, this analysis showed that conditional on taking-up a job, participants became more likely than non-participants to (partly or fully) rely on disability insurance. In fact, these estimates are close to those obtained in analyses in which we compared participants to non-participants who were not necessarily classified as occupationally disabled. That implies that the jobseekers with disabilities who found a new job were not more likely to leave the labour force through disability retirement than otherwise similar jobseekers without occupational disabilities. Hence, these estimates are more likely to serve as an ample lower (upper) bound of the "true" estimate of the total effect of participation in the wage subsidy program on non-subsidised employment (disability retirement).

A similar argument, obviously, applies to our main analysis: The sample of participants is also likely to be a positively selected group of jobseekers with disabilities because they were able to get a new job, although subsidised. Whether or not our estimates can be interpreted as causal effects of the wage subsidy program, hinges on the extent to which we are willing to assume that there are no other characteristics left unobserved that are correlated with both program assignment and the outcomes (i.e. the unconfoundedness assumption). The participants and non-participants are not only nearly identical in terms of the usual background characteristics but also in terms of the type of impairments and 8-year labour market, sickness, and hospitalisation histories, but we lack a measure of to what extent the impairment limit their work capacity. One might argue that, in particular, the 8-year pre-program measures of the outcomes should serve as proxies for such unobserved characteristics, but our indirect test of the unconfoundedness assumption partly questioned its validity. Hence, we will not claim without reservation that our estimates correspond to the causal effects of the wage subsidy program, but only that they are differences between participants and observably very similar non-participants.

To conclude, the wage subsidy program, targeted to jobseekers with occupational disabilities, seems to have been associated with both positive and negative outcomes in terms of the participants' future labour market situation. On the one hand, participants were to a much larger extent found in non-subsidised employment. On the other hand, disability retirement was somewhat less common among participants. Moreover, the overall (subsidised or non-subsidised) employment rate was higher, due to a considerable percentage of the participants who seems to have remained in subsidised employment over a (long) period of time. Hence, the program was associated with substantial locking-in effects, and a comparison with the findings in Jaenichen and Stephan (2011) might suggest that the "soft" time limits of the subsidies in Sweden, compared to those in Germany, imply unnecessarily large locking-in effects. But, given that disability, and the associated 
reduction in work capacity, in many cases is permanent (or even deteriorating), nonsubsidised employment might not be a realistic goal for all. For some, the realistic goal might instead be to be able to remain in subsidised employment and not leaving the labour force through disability retirement.

\section{Endnotes}

${ }^{1}$ Self-reported disability prevalence in OECD member countries ranges from 6 percent (South Korea) to over 20 percent (Estonia, Hungary and Denmark), with an OECD-average of about 14 percent of the working-age population (OECD 2010).

${ }^{2}$ However, there are only a few studies on the causal impact of acquiring a disability on labour market outcomes. Lechner and Vazquez-Alvarez (2011) use matching methods and the exact timing of when workers in Germany become disabled in legal terms, and report that the probability of working is almost 10 percent higher among those without disabilities, and that the earnings differential is about 16 percent. Similarly, Cervini-Plá et al. (2016) estimate the income loss of individuals in Spain who become disabled due to an exogenous disability shock, and find substantial negative short and long-term effects.

${ }^{3}$ See Baert (2016) and Deuchert and Kauer (2017) for recent empirical evidence.

${ }^{4}$ See, for instance, Calmfors et al. (2004) for a discussion on the mechanism of lockingin effects on the Swedish labour market, and van Ours (2004) for empirical findings for the Slovak republic.

${ }^{5}$ Examples of studies of wage subsidies targeted to other disadvantaged groups include Forslund et al. (2004), Huttunen et al. (2013), and Schünemann et al. (2015).

${ }^{6}$ In Deuchert and Kauer (2017), Swiss adolescents seeking regular employment, at the end of a sheltered dual-track vocational education and training program, and who were eligible for the hiring subsidy, each submitted several applications where the eligibility for the subsidy was randomly disclosed or not.

${ }^{7}$ In Baert (2016), a correspondence test was performed in Belgium, in which fictitious applications were sent to real vacancies. Two similar applications were sent to each vacancy, whereof one disclosed a disability. In half of the latter, entitlement to a subsidy for individuals with disabilities who are leaving school after special secondary education was disclosed.

${ }^{8}$ In Gupta and Larsen (2010), a wage subsidy scheme targeted to individuals with longterm disabilities whose work capacity was reduced by at least a third was evaluated using Danish administrative register data. The outcomes of individuals within the targeted group were compared to those of observably similar long-term disabled individuals whose work capacity was reduced by less than one third.

${ }^{9}$ Gupta and Larsen (2010) exploited the fact that the lower subsidy level applied to governmental employers, but not to private, municipal, and regional employers. Hence, using administrative register data, they compared the workforces and hiring responses of state-owned firms to municipal/regional firms.

${ }^{10}$ Similar findings are reported in Furdas (2015).

${ }^{11}$ In July 2000, codes 20, 30, and 40 were replaced by two codes each (i.e., 21-22, 3132 , and 41-42, respectively) also categorizing the severity of the impairment. At the same time three new codes were introduced, 91, 92, and 93. In all analyses, the codes 21-22, $31-32$, and 41-42 have been collapsed to correspond to the old codes of 20,30, and 40, respectively. 
${ }^{12}$ More detailed descriptions, including a discussion about the incentives of the PES to provide a disability code, and of the job seekers to obtain one, is given in Angelov and Eliason (2018) and Johansson and Skedinger (2009).

${ }^{13}$ Socio-medical disability is a code that lacks an international equivalent. The impairments included in this code are caused by social difficulties that have led to long-lasting need of means-tested social benefits or by a complex of relational problems, substance abuse, criminality, and a difficult childhood and adolescence.

${ }^{14}$ In 2000 , there were also a number of other special measures and programs targeted at jobseekers with disabilities: (1) support for working aids in the workplace, (2) support for a personal assistant, (3) special support while starting a business, (4) sheltered employment at the state-owned company Samhall, and (5) sheltered employment with a public-sector employer.

${ }^{15}$ The wage subsidy can be granted for 1) new employees, 2) when an employee returns to work after being on full-time disability retirement, and 3) when an employee's work capacity is reduced within three years from last having had subsidised employment.

${ }^{16}$ The ceiling was SEK $13,700(\approx$ EUR 1370) per month but increased to SEK 15,200 $(\approx$ EUR 1520$)$ and SEK $16700(\approx$ EUR 1670) in 2005 and 2006, respectively (the currency rate used here and in the rest of the paper is SEK $1 \approx$ EUR 0.10 as of December 11, 2017).

${ }^{17}$ Apart from the wage subsidy, the employer can be reimbursed for additional costs of at most SEK 70 per day ( $\approx$ EUR $7 /$ day) for employees whose wage subsidy rate is at least 80 percent.

${ }^{18}$ During the whole program, the employer has to claim the wage subsidy each month, and the subsidy amount is paid out monthly in arrears.

${ }^{19}$ Although the employer can be either public or private, it has to meet some legal requirements, such as being registered as an employer at the Swedish Tax Agency, not having a record of payment failures at the Swedish Enforcement Administration, and having a collective agreement or comparable employee protection insurance.

${ }^{20}$ Those with a temporarily reduced work capacity would instead be eligible for sickness insurance.

${ }^{21}$ All income measures in LOUISE/LISA are annual measures.

${ }^{22}$ Being registered as jobseekers with the PES implies in about half of cases that they were full-time unemployed. The others were, for example, part-time unemployed and employed job-changers. The latter group consists of individuals who need assistance from the PES in their search for a new job. We investigate whether our results are sensitive to the exclusion of all jobseeker who were not full-time unemployed in an additional analysis in Section 4.4.3.

${ }^{23}$ A limited number of observations with missing information were also excluded.

${ }^{24}$ Although we stated in Section 3.1.1 that Statistics Sweden's longitudinal databases (LOUISE/LISA) contain annual measures only, the employment measure is for the month of November only. It is a register-based measure constructed to imitate the ILO's definition of being employed (i.e., paid work for at least one hour during the reference week).

${ }^{25}$ Besides the targeted wage subsidy program under study, there were 12 additional programs involving wage subsidies.

${ }^{26}$ We return to this issue in Section 4.4.

${ }^{27}$ See Imbens and Wooldridge (2009) for a review of methods in the program evaluation literature. 
${ }^{28}$ Since there is no particular matching/weighting estimator that is always preferable, we chose the IPW because it is simple to implement and fast to estimate. However, Busso et al. (2009) found that IPW outperform most matching estimators.

${ }^{29}$ This is the normalized version of IPW, where the weighting function sums to one as recommended in, e.g., Imbens (2004).

${ }^{30}$ Similar estimators have been used in, e.g., Fitzenberger et al. (2013) and Caliendo et al. (2011).

${ }^{31}$ This assumption is usually referred to as the exchangeability, ignorable treatment assignment, unconfoundedness, or conditional independence assumption.

${ }^{32}$ However, in the probit estimations, 469 non-participants were dropped, because they had values of $X$ that predicted non-participation perfectly. Hence, although the data satisfy this condition for the ATET, they do not satisfy the corresponding condition for the average treatment effect (ATE), i.e., $0<p(X)<1$.

${ }^{33}$ There is only one participant with a propensity score larger than the largest propensity score among the non-participants.

${ }^{34}$ Caliendo and Kopeinig (2008) note that in most empirical studies a value of $3-5$ is deemed sufficient.

${ }^{35}$ Rosenbaum and Rubin (1985) considered a value of 20 to be "substantial".

${ }^{36}$ For brevity, in the following text, we refer to the inverse-probability-weighted comparison group of non-participants simply as "non-participants".

${ }^{37}$ During the eight-year pre-program period we would not expect any differences in outcomes between the participants and non-participants.

${ }^{38}$ The quotation marks around post-program are motivated by the fact that the period starts in the year of (potential) program enrolment and not by the expiration of the wage subsidy.

${ }^{39}$ Note that even though this is the year of (potential) program enrolment, we should, for at least two reasons, not expect the employment rate to be zero for any of the two groups: (1) employment is measured in the month of November (i.e., someone who was unemployed during January-October would still be counted as employed if starting a job in November); and (2) not all who registered as jobseekers at the PES were full-time unemployed, as some were, for example, part-time unemployed and so called job-changers (in Section 4.4.3, we present the results from an investigation of the sensitivity of our results to dropping all who were not full-time unemployed at the time of registration with the PES).

${ }^{40}$ Because the employment measure refers to the month of November it is not the full 100 percent.

${ }^{41}$ Recall that by switching employers, a new four-year period can be granted, and that the time limit also can be extended under "certain circumstances".

${ }^{42} \mathrm{~A}$ summary of assessments of the common support and covariate balance can be found in Appendix: Tables 13 and 14.

${ }^{43}$ Those jobseekers may instead be eligible for sheltered employment.

${ }^{44}$ The starting dates for subsidised employment are available from the PES (since they refer to the starting date of a program administrated by the PES), but not the starting dates for non-subsidized employment. Hence, we relied on our measures in the month of November, which we also used as outcomes.

${ }^{45}$ Consequently we dropped the few jobseekers who registered at the PES in November or December of that year.

${ }^{46}$ Note that we do not only exclude $Y_{t-8}, Y_{t-7}, \ldots, Y_{t-2}$, but rather all covariates measured in $t-8$ to $t-2$. 


\section{Appendix}

Table 10 Summary statistics of the background characteristics for participants $(D=1)$ and non-participants $(D=0)$ and assessments of the covariate balance, before and after the inverse probability weighting (IPW)

\begin{tabular}{|c|c|c|c|c|c|c|c|c|}
\hline & \multicolumn{4}{|c|}{ Before IPW } & \multicolumn{4}{|c|}{ After IPW } \\
\hline & \multicolumn{2}{|c|}{ Mean } & \multicolumn{2}{|l|}{ Balance } & \multicolumn{2}{|l|}{ Mean } & \multicolumn{2}{|l|}{ Balance } \\
\hline & $D=1$ & $D=0$ & ASDM $^{a}$ & $p$-value ${ }^{b}$ & $D=1$ & $D=0$ & $\mathrm{ASDM}^{\mathrm{a}}$ & $p$-value \\
\hline Female & 0.356 & 0.485 & 26.335 & 0.000 & 0.356 & 0.360 & 0.695 & 0.730 \\
\hline Foreign born & 0.137 & 0.189 & 14.015 & 0.000 & 0.137 & 0.141 & 1.042 & 0.602 \\
\hline \multicolumn{9}{|l|}{ Age } \\
\hline $25-29$ years & 0.128 & 0.143 & 4.345 & 0.029 & 0.128 & 0.131 & 0.983 & 0.625 \\
\hline $30-34$ years & 0.162 & 0.184 & 5.938 & 0.003 & 0.162 & 0.158 & 0.885 & 0.661 \\
\hline $35-39$ years & 0.190 & 0.197 & 1.779 & 0.365 & 0.190 & 0.191 & 0.290 & 0.886 \\
\hline 40-44 years & 0.175 & 0.178 & 1.027 & 0.600 & 0.175 & 0.175 & 0.241 & 0.905 \\
\hline 45-49 years & 0.170 & 0.159 & 2.782 & 0.150 & 0.170 & 0.169 & 0.181 & 0.929 \\
\hline $50-54$ years & 0.176 & 0.138 & 10.445 & 0.000 & 0.176 & 0.175 & 0.377 & 0.853 \\
\hline \multicolumn{9}{|l|}{ Marital status } \\
\hline Never-married & 0.457 & 0.489 & 6.504 & 0.001 & 0.457 & 0.456 & 0.138 & 0.946 \\
\hline Married & 0.344 & 0.295 & 10.521 & 0.000 & 0.344 & 0.339 & 1.005 & 0.622 \\
\hline Divorced & 0.194 & 0.208 & 3.502 & 0.076 & 0.194 & 0.199 & 1.208 & 0.549 \\
\hline Widowed & 0.005 & 0.008 & 3.038 & 0.150 & 0.005 & 0.006 & 0.853 & 0.662 \\
\hline \multicolumn{9}{|l|}{ Any children } \\
\hline 0-6 years & 0.173 & 0.197 & 6.070 & 0.002 & 0.173 & 0.173 & 0.011 & 0.996 \\
\hline 7-17 years & 0.315 & 0.318 & 0.693 & 0.723 & 0.315 & 0.314 & 0.070 & 0.972 \\
\hline \multicolumn{9}{|l|}{ Attained education } \\
\hline Compulsory & 0.362 & 0.368 & 1.196 & 0.541 & 0.362 & 0.361 & 0.290 & 0.886 \\
\hline Upper secondary & 0.565 & 0.554 & 2.165 & 0.268 & 0.565 & 0.566 & 0.250 & 0.902 \\
\hline University & 0.071 & 0.075 & 1.649 & 0.404 & 0.071 & 0.071 & 0.018 & 0.993 \\
\hline Unknown & 0.002 & 0.003 & 1.508 & 0.471 & 0.002 & 0.002 & 0.240 & 0.906 \\
\hline \multicolumn{9}{|l|}{ Job search } \\
\hline Locally only & 0.907 & 0.889 & 5.836 & 0.004 & 0.907 & 0.905 & 0.561 & 0.780 \\
\hline Full-time only & 0.433 & 0.458 & 4.962 & 0.011 & 0.433 & 0.431 & 0.532 & 0.793 \\
\hline Part-time only & 0.262 & 0.168 & 22.943 & 0.000 & 0.262 & 0.262 & 0.036 & 0.986 \\
\hline Full- or part-time & 0.304 & 0.374 & 14.653 & 0.000 & 0.304 & 0.307 & 0.647 & 0.748 \\
\hline \multicolumn{9}{|c|}{ Quarter of (potential) program enrolment } \\
\hline Jan-Mar & 0.217 & 0.267 & 11.723 & 0.000 & 0.217 & 0.217 & 0.000 & 1.000 \\
\hline Apr-Jun & 0.231 & 0.265 & 7.835 & 0.000 & 0.231 & 0.231 & 0.000 & 1.000 \\
\hline Jul-Sep & 0.235 & 0.238 & 0.713 & 0.716 & 0.235 & 0.235 & 0.000 & 1.000 \\
\hline Oct-Dec & 0.317 & 0.230 & 19.616 & 0.000 & 0.317 & 0.317 & 0.000 & 1.000 \\
\hline \multicolumn{9}{|c|}{ Time since registration with the PESC } \\
\hline $1-3$ months & 0.483 & 0.352 & 26.952 & 0.000 & 0.483 & 0.483 & 0.000 & 1.000 \\
\hline $4-6$ months & 0.215 & 0.228 & 2.984 & 0.130 & 0.215 & 0.215 & 0.000 & 1.000 \\
\hline 7-9 months & 0.162 & 0.219 & 14.461 & 0.000 & 0.162 & 0.162 & 0.000 & 1.000 \\
\hline 10-12 months & 0.139 & 0.201 & 16.737 & 0.000 & 0.139 & 0.139 & 0.000 & 1.000 \\
\hline \multicolumn{9}{|c|}{ Time since disability coding ${ }^{d}$} \\
\hline 1-3 months & 0.638 & 0.441 & 40.367 & 0.000 & 0.638 & 0.638 & 0.000 & 1.000 \\
\hline $4-6$ months & 0.172 & 0.243 & 17.576 & 0.000 & 0.172 & 0.172 & 0.000 & 1.000 \\
\hline 7-9 months & 0.119 & 0.187 & 18.969 & 0.000 & 0.119 & 0.119 & 0.000 & 1.000 \\
\hline 10-12 months & 0.070 & 0.129 & 19.511 & 0.000 & 0.070 & 0.070 & 0.000 & 1.000 \\
\hline
\end{tabular}


Table 10 Summary statistics of the background characteristics for participants $(D=1)$ and non-participants $(D=0)$ and assessments of the covariate balance, before and after the inverse probability weighting (IPW) (Continued)

\begin{tabular}{|c|c|c|c|c|c|c|c|c|}
\hline & \multicolumn{4}{|c|}{ Before IPW } & \multicolumn{4}{|c|}{ After IPW } \\
\hline & \multicolumn{2}{|l|}{ Mean } & \multicolumn{2}{|l|}{ Balance } & \multicolumn{2}{|l|}{ Mean } & \multicolumn{2}{|l|}{ Balance } \\
\hline & $D=1$ & $D=0$ & $\mathrm{ASDM}^{\mathrm{a}}$ & $p$-value ${ }^{b}$ & $D=1$ & $D=0$ & $\mathrm{ASDM}^{\mathrm{a}}$ & $p$-value ${ }^{b}$ \\
\hline \multicolumn{9}{|l|}{ Disability code } \\
\hline 11 & 0.030 & 0.022 & 4.796 & 0.008 & 0.030 & 0.029 & 0.476 & 0.817 \\
\hline 20 & 0.138 & 0.176 & 10.615 & 0.000 & 0.138 & 0.135 & 0.656 & 0.745 \\
\hline 30 & 0.105 & 0.100 & 1.769 & 0.360 & 0.105 & 0.104 & 0.214 & 0.916 \\
\hline 40 & 0.043 & 0.028 & 8.044 & 0.000 & 0.043 & 0.041 & 0.858 & 0.678 \\
\hline 51 & 0.156 & 0.169 & 3.766 & 0.058 & 0.156 & 0.157 & 0.276 & 0.890 \\
\hline 61 & 0.006 & 0.007 & 1.529 & 0.452 & 0.006 & 0.006 & 0.287 & 0.889 \\
\hline 71 & 0.010 & 0.011 & 1.101 & 0.582 & 0.010 & 0.011 & 0.569 & 0.774 \\
\hline 81 & 0.008 & 0.002 & 7.657 & 0.000 & 0.008 & 0.008 & 0.118 & 0.957 \\
\hline 91 & 0.027 & 0.028 & 0.682 & 0.729 & 0.027 & 0.029 & 1.637 & 0.412 \\
\hline 92 & 0.014 & 0.014 & 0.019 & 0.992 & 0.014 & 0.014 & 0.245 & 0.904 \\
\hline 93 & 0.436 & 0.413 & 4.585 & 0.019 & 0.436 & 0.437 & 0.294 & 0.885 \\
\hline Multiple codes & 0.076 & 0.057 & 7.900 & 0.000 & 0.076 & 0.078 & 0.508 & 0.804 \\
\hline \multicolumn{9}{|c|}{ Unsubsidised employment in November } \\
\hline$t-1$ & 0.415 & 0.268 & 31.352 & 0.000 & 0.415 & 0.408 & 1.347 & 0.508 \\
\hline$t-2$ & 0.429 & 0.297 & 27.750 & 0.000 & 0.429 & 0.424 & 1.144 & 0.573 \\
\hline$t-3$ & 0.432 & 0.297 & 28.469 & 0.000 & 0.432 & 0.426 & 1.328 & 0.514 \\
\hline$t-4$ & 0.473 & 0.339 & 27.408 & 0.000 & 0.473 & 0.467 & 1.062 & 0.601 \\
\hline$t-5$ & 0.482 & 0.356 & 25.734 & 0.000 & 0.482 & 0.476 & 1.204 & 0.553 \\
\hline$t-6$ & 0.479 & 0.371 & 21.971 & 0.000 & 0.479 & 0.472 & 1.439 & 0.478 \\
\hline$t-7$ & 0.534 & 0.441 & 18.683 & 0.000 & 0.534 & 0.531 & 0.575 & 0.776 \\
\hline$t-8$ & 0.595 & 0.513 & 16.651 & 0.000 & 0.595 & 0.592 & 0.634 & 0.754 \\
\hline \multicolumn{9}{|c|}{ Employment in November } \\
\hline$t-1$ & 0.484 & 0.303 & 37.616 & 0.000 & 0.484 & 0.479 & 0.984 & 0.628 \\
\hline$t-2$ & 0.525 & 0.357 & 34.420 & 0.000 & 0.525 & 0.521 & 0.910 & 0.653 \\
\hline$t-3$ & 0.525 & 0.358 & 34.033 & 0.000 & 0.525 & 0.520 & 0.931 & 0.646 \\
\hline$t-4$ & 0.559 & 0.400 & 32.317 & 0.000 & 0.559 & 0.554 & 0.966 & 0.633 \\
\hline$t-5$ & 0.582 & 0.434 & 29.891 & 0.000 & 0.582 & 0.576 & 1.168 & 0.562 \\
\hline$t-6$ & 0.559 & 0.440 & 23.941 & 0.000 & 0.559 & 0.552 & 1.512 & 0.454 \\
\hline$t-7$ & 0.575 & 0.481 & 19.000 & 0.000 & 0.575 & 0.570 & 1.033 & 0.609 \\
\hline$t-8$ & 0.616 & 0.544 & 14.718 & 0.000 & 0.616 & 0.612 & 0.813 & 0.687 \\
\hline \multicolumn{9}{|c|}{ Positive labour income ${ }^{g}$} \\
\hline$t-1$ & 0.677 & 0.533 & 29.762 & 0.000 & 0.677 & 0.673 & 0.897 & 0.655 \\
\hline$t-2$ & 0.684 & 0.548 & 28.232 & 0.000 & 0.684 & 0.678 & 1.222 & 0.543 \\
\hline$t-3$ & 0.689 & 0.563 & 26.251 & 0.000 & 0.689 & 0.683 & 1.157 & 0.564 \\
\hline$t-4$ & 0.711 & 0.601 & 23.400 & 0.000 & 0.711 & 0.707 & 0.901 & 0.653 \\
\hline$t-5$ & 0.728 & 0.642 & 18.670 & 0.000 & 0.728 & 0.723 & 1.172 & 0.559 \\
\hline$t-6$ & 0.718 & 0.643 & 16.114 & 0.000 & 0.718 & 0.713 & 1.135 & 0.572 \\
\hline$t-7$ & 0.721 & 0.654 & 14.321 & 0.000 & 0.721 & 0.715 & 1.170 & 0.561 \\
\hline$t-8$ & 0.778 & 0.730 & 11.248 & 0.000 & 0.778 & 0.775 & 0.615 & 0.760 \\
\hline \multicolumn{9}{|l|}{ Labour income ${ }^{\mathrm{g}}$} \\
\hline$t-1$ & 72.224 & 45.710 & 33.695 & 0.000 & 72.224 & 71.277 & 1.099 & 0.588 \\
\hline$t-2$ & 81.915 & 52.257 & 34.749 & 0.000 & 81.915 & 80.663 & 1.358 & 0.507 \\
\hline$t-3$ & 86.139 & 56.785 & 33.905 & 0.000 & 86.139 & 85.005 & 1.225 & 0.545 \\
\hline$t-4$ & 91.009 & 61.226 & 34.060 & 0.000 & 91.009 & 89.864 & 1.228 & 0.547 \\
\hline$t-5$ & 91.360 & 64.269 & 31.991 & 0.000 & 91.360 & 90.466 & 0.980 & 0.628 \\
\hline$t-6$ & 86.061 & 63.562 & 26.554 & 0.000 & 86.061 & 85.033 & 1.132 & 0.577 \\
\hline$t-7$ & 86.508 & 66.160 & 23.501 & 0.000 & 86.508 & 85.417 & 1.176 & 0.562 \\
\hline$t-8$ & 99.580 & 78.250 & 23.758 & 0.000 & 99.580 & 98.810 & 0.811 & 0.691 \\
\hline
\end{tabular}


Table 10 Summary statistics of the background characteristics for participants $(D=1)$ and non-participants $(D=0)$ and assessments of the covariate balance, before and after the inverse probability weighting (IPW) (Continued)

\begin{tabular}{|c|c|c|c|c|c|c|c|c|}
\hline & \multicolumn{4}{|c|}{ Before IPW } & \multicolumn{4}{|c|}{ After IPW } \\
\hline & \multicolumn{2}{|c|}{ Mean } & \multicolumn{2}{|l|}{ Balance } & \multicolumn{2}{|c|}{ Mean } & \multicolumn{2}{|l|}{ Balance } \\
\hline & $D=1$ & $D=0$ & $\mathrm{ASDM}^{\mathrm{a}}$ & $p$-value ${ }^{b}$ & $D=1$ & $D=0$ & $\mathrm{ASDM}^{\mathrm{a}}$ & $p$-value ${ }^{b}$ \\
\hline \multicolumn{9}{|c|}{ Disability insurance receipt $^{f}$} \\
\hline$t-1$ & 0.154 & 0.103 & 15.354 & 0.000 & 0.154 & 0.153 & 0.204 & 0.922 \\
\hline$t-2$ & 0.133 & 0.088 & 14.201 & 0.000 & 0.133 & 0.133 & 0.082 & 0.968 \\
\hline$t-3$ & 0.116 & 0.075 & 14.106 & 0.000 & 0.116 & 0.116 & 0.173 & 0.933 \\
\hline$t-4$ & 0.099 & 0.065 & 12.326 & 0.000 & 0.099 & 0.098 & 0.309 & 0.881 \\
\hline$t-5$ & 0.085 & 0.055 & 11.790 & 0.000 & 0.085 & 0.085 & 0.238 & 0.908 \\
\hline$t-6$ & 0.069 & 0.047 & 9.372 & 0.000 & 0.069 & 0.068 & 0.364 & 0.860 \\
\hline$t-7$ & 0.062 & 0.038 & 11.004 & 0.000 & 0.062 & 0.062 & 0.084 & 0.968 \\
\hline$t-8$ & 0.048 & 0.029 & 10.021 & 0.000 & 0.048 & 0.048 & 0.096 & 0.963 \\
\hline \multicolumn{9}{|c|}{ Disability insurance amount ${ }^{9}$} \\
\hline$t-1$ & 11.312 & 7.246 & 14.837 & 0.000 & 11.312 & 11.280 & 0.105 & 0.960 \\
\hline$t-2$ & 9.866 & 6.080 & 14.795 & 0.000 & 9.866 & 9.852 & 0.047 & 0.982 \\
\hline$t-3$ & 8.217 & 5.121 & 13.324 & 0.000 & 8.217 & 8.197 & 0.079 & 0.969 \\
\hline$t-4$ & 6.899 & 4.386 & 11.830 & 0.000 & 6.899 & 6.853 & 0.195 & 0.924 \\
\hline$t-5$ & 5.961 & 3.890 & 10.279 & 0.000 & 5.961 & 5.880 & 0.371 & 0.858 \\
\hline$t-6$ & 5.090 & 3.405 & 8.883 & 0.000 & 5.090 & 5.083 & 0.038 & 0.985 \\
\hline$t-7$ & 4.438 & 2.672 & 10.381 & 0.000 & 4.438 & 4.457 & 0.103 & 0.960 \\
\hline$t-8$ & 3.481 & 1.997 & 9.945 & 0.000 & 3.481 & 3.513 & 0.194 & 0.926 \\
\hline \multicolumn{9}{|c|}{ Unemployment insurance receipt $^{f}$} \\
\hline$t-1$ & 0.311 & 0.563 & 52.477 & 0.000 & 0.311 & 0.315 & 0.885 & 0.658 \\
\hline$t-2$ & 0.342 & 0.552 & 43.027 & 0.000 & 0.342 & 0.344 & 0.418 & 0.835 \\
\hline$t-3$ & 0.383 & 0.568 & 37.758 & 0.000 & 0.383 & 0.384 & 0.304 & 0.880 \\
\hline$t-4$ & 0.384 & 0.550 & 33.681 & 0.000 & 0.384 & 0.387 & 0.642 & 0.750 \\
\hline$t-5$ & 0.399 & 0.541 & 28.661 & 0.000 & 0.399 & 0.404 & 0.965 & 0.632 \\
\hline$t-6$ & 0.418 & 0.524 & 21.409 & 0.000 & 0.418 & 0.423 & 0.913 & 0.651 \\
\hline$t-7$ & 0.405 & 0.498 & 18.856 & 0.000 & 0.405 & 0.407 & 0.592 & 0.770 \\
\hline$t-8$ & 0.350 & 0.442 & 18.828 & 0.000 & 0.350 & 0.352 & 0.420 & 0.835 \\
\hline \multicolumn{9}{|c|}{ Unemployment insurance amount ${ }^{\mathrm{g}}$} \\
\hline$t-1$ & 17.071 & 36.137 & 45.546 & 0.000 & 17.071 & 17.406 & 0.939 & 0.633 \\
\hline$t-2$ & 23.065 & 41.139 & 36.611 & 0.000 & 23.065 & 23.379 & 0.708 & 0.721 \\
\hline$t-3$ & 27.459 & 45.236 & 34.713 & 0.000 & 27.459 & 27.696 & 0.502 & 0.801 \\
\hline$t-4$ & 27.528 & 42.976 & 30.798 & 0.000 & 27.528 & 27.769 & 0.517 & 0.795 \\
\hline$t-5$ & 27.402 & 40.067 & 26.060 & 0.000 & 27.402 & 27.698 & 0.647 & 0.746 \\
\hline$t-6$ & 29.678 & 38.172 & 17.365 & 0.000 & 29.678 & 29.841 & 0.346 & 0.863 \\
\hline$t-7$ & 29.706 & 36.159 & 12.992 & 0.000 & 29.706 & 29.907 & 0.412 & 0.838 \\
\hline$t-8$ & 24.705 & 31.312 & 13.738 & 0.000 & 24.705 & 24.722 & 0.035 & 0.986 \\
\hline \multicolumn{9}{|c|}{ Sickness insurance receipt ${ }^{f}$} \\
\hline$t-1$ & 0.501 & 0.477 & 4.916 & 0.012 & 0.501 & 0.505 & 0.805 & 0.691 \\
\hline$t-2$ & 0.431 & 0.414 & 3.344 & 0.086 & 0.431 & 0.432 & 0.254 & 0.900 \\
\hline$t-3$ & 0.334 & 0.359 & 5.064 & 0.010 & 0.334 & 0.334 & 0.158 & 0.938 \\
\hline$t-4$ & 0.346 & 0.375 & 6.026 & 0.002 & 0.346 & 0.345 & 0.172 & 0.932 \\
\hline$t-5$ & 0.360 & 0.377 & 3.586 & 0.067 & 0.360 & 0.361 & 0.183 & 0.928 \\
\hline$t-6$ & 0.346 & 0.379 & 6.959 & 0.000 & 0.346 & 0.345 & 0.147 & 0.942 \\
\hline$t-7$ & 0.397 & 0.430 & 6.764 & 0.001 & 0.397 & 0.395 & 0.478 & 0.813 \\
\hline$t-8$ & 0.447 & 0.500 & 10.744 & 0.000 & 0.447 & 0.446 & 0.029 & 0.989 \\
\hline
\end{tabular}


Table 10 Summary statistics of the background characteristics for participants $(D=1)$ and non-participants $(D=0)$ and assessments of the covariate balance, before and after the inverse probability weighting (IPW) (Continued)

\begin{tabular}{|c|c|c|c|c|c|c|c|c|}
\hline & \multicolumn{4}{|c|}{ Before IPW } & \multicolumn{4}{|c|}{ After IPW } \\
\hline & \multicolumn{2}{|l|}{ Mean } & \multicolumn{2}{|l|}{ Balance } & \multicolumn{2}{|c|}{ Mean } & \multicolumn{2}{|l|}{ Balance } \\
\hline & $D=1$ & $D=0$ & ASDM $^{a}$ & $p$-value ${ }^{b}$ & $D=1$ & $D=0$ & $\mathrm{ASDM}^{\mathrm{a}}$ & $p$-value ${ }^{\mathrm{b}}$ \\
\hline \multicolumn{9}{|c|}{ Sickness insurance amount ${ }^{9}$} \\
\hline$t-1$ & 48.962 & 35.501 & 20.424 & 0.000 & 48.962 & 49.173 & 0.294 & 0.886 \\
\hline$t-2$ & 33.148 & 24.776 & 15.550 & 0.000 & 33.148 & 33.156 & 0.014 & 0.995 \\
\hline$t-3$ & 20.413 & 16.484 & 9.397 & 0.000 & 20.413 & 20.425 & 0.026 & 0.990 \\
\hline$t-4$ & 15.663 & 14.609 & 2.931 & 0.120 & 15.663 & 15.790 & 0.336 & 0.868 \\
\hline$t-5$ & 15.969 & 15.199 & 2.074 & 0.276 & 15.969 & 16.017 & 0.125 & 0.951 \\
\hline$t-6$ & 15.850 & 14.552 & 3.548 & 0.059 & 15.850 & 15.761 & 0.233 & 0.909 \\
\hline$t-7$ & 14.987 & 14.414 & 1.577 & 0.408 & 14.987 & 14.977 & 0.024 & 0.990 \\
\hline$t-8$ & 16.558 & 16.413 & 0.361 & 0.851 & 16.558 & 16.492 & 0.160 & 0.937 \\
\hline \multicolumn{9}{|c|}{ Social benefit receipt ${ }^{f}$} \\
\hline$t-1$ & 0.240 & 0.336 & 21.329 & 0.000 & 0.240 & 0.248 & 1.763 & 0.377 \\
\hline$t-2$ & 0.238 & 0.347 & 24.168 & 0.000 & 0.238 & 0.243 & 1.240 & 0.534 \\
\hline$t-3$ & 0.272 & 0.372 & 21.611 & 0.000 & 0.272 & 0.276 & 0.873 & 0.663 \\
\hline$t-4$ & 0.274 & 0.376 & 21.761 & 0.000 & 0.274 & 0.279 & 1.173 & 0.558 \\
\hline$t-5$ & 0.258 & 0.357 & 21.576 & 0.000 & 0.258 & 0.263 & 1.035 & 0.605 \\
\hline$t-6$ & 0.263 & 0.360 & 21.040 & 0.000 & 0.263 & 0.268 & 0.992 & 0.621 \\
\hline$t-7$ & 0.275 & 0.358 & 18.062 & 0.000 & 0.275 & 0.278 & 0.823 & 0.682 \\
\hline$t-8$ & 0.254 & 0.337 & 18.329 & 0.000 & 0.254 & 0.257 & 0.803 & 0.689 \\
\hline \multicolumn{9}{|c|}{ Social benefit amount ${ }^{9}$} \\
\hline$t-1$ & 7.123 & 10.368 & 14.512 & 0.000 & 7.123 & 7.359 & 1.140 & 0.571 \\
\hline$t-2$ & 6.828 & 9.829 & 14.283 & 0.000 & 6.828 & 7.020 & 0.979 & 0.620 \\
\hline$t-3$ & 7.313 & 10.055 & 12.965 & 0.000 & 7.313 & 7.436 & 0.616 & 0.758 \\
\hline$t-4$ & 6.921 & 9.464 & 12.599 & 0.000 & 6.921 & 7.042 & 0.638 & 0.749 \\
\hline$t-5$ & 6.062 & 8.047 & 10.888 & 0.000 & 6.062 & 6.147 & 0.486 & 0.808 \\
\hline$t-6$ & 6.042 & 8.451 & 12.913 & 0.000 & 6.042 & 6.133 & 0.519 & 0.796 \\
\hline$t-7$ & 6.287 & 8.375 & 11.428 & 0.000 & 6.287 & 6.337 & 0.292 & 0.882 \\
\hline$t-8$ & 5.202 & 7.216 & 12.284 & 0.000 & 5.202 & 5.368 & 1.085 & 0.586 \\
\hline \multicolumn{9}{|c|}{ Disability allowance receipt ${ }^{f}$} \\
\hline$t-1$ & 0.042 & 0.027 & 8.069 & 0.000 & 0.042 & 0.041 & 0.468 & 0.823 \\
\hline$t-2$ & 0.039 & 0.026 & 7.554 & 0.000 & 0.039 & 0.038 & 0.334 & 0.873 \\
\hline$t-3$ & 0.037 & 0.024 & 7.399 & 0.000 & 0.037 & 0.037 & 0.020 & 0.992 \\
\hline$t-4$ & 0.034 & 0.024 & 6.209 & 0.001 & 0.034 & 0.034 & 0.149 & 0.943 \\
\hline$t-5$ & 0.034 & 0.023 & 6.692 & 0.000 & 0.034 & 0.034 & 0.134 & 0.949 \\
\hline$t-6$ & 0.032 & 0.021 & 6.396 & 0.000 & 0.032 & 0.032 & 0.056 & 0.979 \\
\hline$t-7$ & 0.030 & 0.021 & 5.584 & 0.002 & 0.030 & 0.029 & 0.060 & 0.977 \\
\hline$t-8$ & 0.028 & 0.019 & 5.703 & 0.001 & 0.028 & 0.028 & 0.258 & 0.901 \\
\hline \multicolumn{9}{|c|}{ Disability allowance amount ${ }^{\mathrm{g}}$} \\
\hline$t-1$ & 0.944 & 0.561 & 8.572 & 0.000 & 0.944 & 0.899 & 0.911 & 0.672 \\
\hline$t-2$ & 0.876 & 0.549 & 7.546 & 0.000 & 0.876 & 0.834 & 0.888 & 0.675 \\
\hline$t-3$ & 0.836 & 0.512 & 7.859 & 0.000 & 0.836 & 0.816 & 0.426 & 0.841 \\
\hline$t-4$ & 0.759 & 0.508 & 6.246 & 0.001 & 0.759 & 0.754 & 0.114 & 0.956 \\
\hline$t-5$ & 0.787 & 0.463 & 7.925 & 0.000 & 0.787 & 0.777 & 0.221 & 0.917 \\
\hline$t-6$ & 0.709 & 0.445 & 7.087 & 0.000 & 0.709 & 0.698 & 0.259 & 0.902 \\
\hline$t-7$ & 0.662 & 0.439 & 6.053 & 0.001 & 0.662 & 0.643 & 0.463 & 0.824 \\
\hline$t-8$ & 0.635 & 0.409 & 6.134 & 0.000 & 0.635 & 0.650 & 0.362 & 0.863 \\
\hline
\end{tabular}


Table 10 Summary statistics of the background characteristics for participants $(D=1)$ and non-participants $(D=0)$ and assessments of the covariate balance, before and after the inverse probability weighting (IPW) (Continued)

\begin{tabular}{|c|c|c|c|c|c|c|c|c|}
\hline & \multicolumn{4}{|c|}{ Before IPW } & \multicolumn{4}{|c|}{ After IPW } \\
\hline & \multicolumn{2}{|l|}{ Mean } & \multicolumn{2}{|l|}{ Balance } & \multicolumn{2}{|l|}{ Mean } & \multicolumn{2}{|l|}{ Balance } \\
\hline & $D=1$ & $D=0$ & ASDM $^{a}$ & $p$-value ${ }^{b}$ & $D=1$ & $D=0$ & $\mathrm{ASDM}^{\mathrm{a}}$ & $p$-value \\
\hline \multicolumn{9}{|c|}{ Hospital in-inpatient care ${ }^{h}$} \\
\hline No of days & 20.775 & 16.074 & 7.310 & 0.000 & 20.775 & 20.928 & 0.195 & 0.923 \\
\hline \multicolumn{9}{|c|}{ Discharge diagnosish } \\
\hline Ch.I & 0.032 & 0.031 & 0.720 & 0.710 & 0.032 & 0.033 & 0.364 & 0.856 \\
\hline Ch. II & 0.025 & 0.028 & 1.973 & 0.325 & 0.025 & 0.024 & 0.599 & 0.767 \\
\hline Ch. III & 0.004 & 0.004 & 0.082 & 0.966 & 0.004 & 0.004 & 0.076 & 0.970 \\
\hline Ch. IV & 0.024 & 0.027 & 1.798 & 0.369 & 0.024 & 0.024 & 0.068 & 0.973 \\
\hline Ch. V & 0.136 & 0.152 & 4.375 & 0.028 & 0.136 & 0.139 & 0.756 & 0.706 \\
\hline Ch. VI & 0.036 & 0.028 & 4.681 & 0.011 & 0.036 & 0.036 & 0.064 & 0.975 \\
\hline Ch. VII & 0.009 & 0.008 & 0.875 & 0.647 & 0.009 & 0.009 & 0.551 & 0.787 \\
\hline Ch. VIII & 0.007 & 0.008 & 1.991 & 0.332 & 0.007 & 0.007 & 0.224 & 0.911 \\
\hline Ch. IX & 0.054 & 0.044 & 4.617 & 0.013 & 0.054 & 0.052 & 0.728 & 0.723 \\
\hline Ch. X & 0.055 & 0.050 & 2.471 & 0.195 & 0.055 & 0.056 & 0.164 & 0.936 \\
\hline Ch. XI & 0.086 & 0.086 & 0.067 & 0.973 & 0.086 & 0.084 & 0.631 & 0.756 \\
\hline Ch. XII & 0.015 & 0.015 & 0.035 & 0.986 & 0.015 & 0.015 & 0.364 & 0.857 \\
\hline Ch. XIII & 0.104 & 0.078 & 9.073 & 0.000 & 0.104 & 0.104 & 0.033 & 0.987 \\
\hline Ch. XIV & 0.054 & 0.067 & 5.606 & 0.006 & 0.054 & 0.056 & 0.683 & 0.734 \\
\hline Ch. XV & 0.104 & 0.159 & 16.198 & 0.000 & 0.104 & 0.105 & 0.062 & 0.975 \\
\hline Ch. XVII & 0.012 & 0.008 & 4.022 & 0.023 & 0.012 & 0.012 & 0.241 & 0.907 \\
\hline Ch. XVIII & 0.114 & 0.115 & 0.314 & 0.872 & 0.114 & 0.115 & 0.220 & 0.914 \\
\hline Ch. XIX & 0.211 & 0.193 & 4.487 & 0.020 & 0.211 & 0.209 & 0.408 & 0.841 \\
\hline \multicolumn{9}{|c|}{ County of residence } \\
\hline Stockholm & 0.191 & 0.157 & 9.005 & 0.000 & 0.191 & 0.196 & 1.293 & 0.523 \\
\hline Uppsala & 0.034 & 0.025 & 4.998 & 0.006 & 0.034 & 0.032 & 0.626 & 0.758 \\
\hline Södermanland & 0.025 & 0.030 & 2.939 & 0.147 & 0.025 & 0.024 & 0.646 & 0.749 \\
\hline Östergötland & 0.027 & 0.049 & 11.073 & 0.000 & 0.027 & 0.027 & 0.332 & 0.871 \\
\hline Jönköping & 0.021 & 0.028 & 4.283 & 0.038 & 0.021 & 0.021 & 0.184 & 0.927 \\
\hline Kronoberg & 0.018 & 0.014 & 2.555 & 0.170 & 0.018 & 0.017 & 0.653 & 0.753 \\
\hline Kalmar & 0.022 & 0.031 & 5.136 & 0.014 & 0.022 & 0.022 & 0.260 & 0.897 \\
\hline Gotland & 0.005 & 0.012 & 7.237 & 0.001 & 0.005 & 0.005 & 0.543 & 0.795 \\
\hline Blekinge & 0.020 & 0.024 & 2.995 & 0.142 & 0.020 & 0.021 & 0.593 & 0.765 \\
\hline Skåne & 0.092 & 0.132 & 12.829 & 0.000 & 0.092 & 0.092 & 0.215 & 0.914 \\
\hline Halland & 0.016 & 0.022 & 4.208 & 0.043 & 0.016 & 0.016 & 0.367 & 0.855 \\
\hline Vätra Götaland & 0.153 & 0.138 & 4.369 & 0.022 & 0.153 & 0.151 & 0.696 & 0.731 \\
\hline Värmland & 0.064 & 0.050 & 6.169 & 0.001 & 0.064 & 0.063 & 0.353 & 0.865 \\
\hline Örebro & 0.032 & 0.031 & 0.963 & 0.618 & 0.032 & 0.034 & 0.667 & 0.739 \\
\hline Västmanland & 0.047 & 0.029 & 9.200 & 0.000 & 0.047 & 0.047 & 0.096 & 0.963 \\
\hline Dalarnas & 0.039 & 0.043 & 2.204 & 0.270 & 0.039 & 0.039 & 0.059 & 0.977 \\
\hline Gävleborg & 0.030 & 0.039 & 5.079 & 0.014 & 0.030 & 0.030 & 0.517 & 0.796 \\
\hline Västernorrland & 0.047 & 0.036 & 5.800 & 0.002 & 0.047 & 0.045 & 0.793 & 0.699 \\
\hline Jämtland & 0.023 & 0.014 & 6.426 & 0.000 & 0.023 & 0.023 & 0.044 & 0.983 \\
\hline Västerbotten & 0.054 & 0.042 & 5.402 & 0.003 & 0.054 & 0.053 & 0.157 & 0.938 \\
\hline Norrbotten & 0.041 & 0.056 & 7.025 & 0.001 & 0.041 & 0.042 & 0.677 & 0.734 \\
\hline
\end{tabular}

${ }^{a}$ ASDM refers to the absolute value of the standardised difference in means.

${ }^{\mathrm{b}}$ The $p$-value from a $t$-test for equality of means.

'Refers to the duration from registration with the PES to (potential) program enrolment.

${ }^{\mathrm{d}}$ Refers to the duration from being coded as occupationally disabled to (potential) program enrolment.

esee Appendix: Table 11 for an explanation of the occupational disability codes.

${ }^{f}$ Refers to a positive annual amount.

${ }^{9}$ Annual amounts in SEK 1000 ( $\approx$ EUR 100).

${ }^{\mathrm{h}}$ The categories refer to ICD-chapters. The content of each chapter is found in Appendix: Table 12 
Table 11 The PES's occupational disability codes

\begin{tabular}{ll}
\hline Code & Description \\
\hline 11 & Cardio, vascular, and/or lung disease \\
$20-22$ & Hearing impairment and deafness \\
$30-32$ & Visual impairment \\
$40-42$ & Motor disability \\
51 & Other somatically related disabilities \\
61 & Mental disability \\
71 & Learning disability \\
81 & Socio-medical disability \\
91 & Asthma, allergy, and hypersensitivity \\
92 & Dyslexia and specific learning difficulties \\
93 & Acquired brain injury \\
\hline
\end{tabular}

Table 12 The hospital inpatient categories based on the ICD-10 chapters

\begin{tabular}{|c|c|c|}
\hline Chapter & Block & Description \\
\hline I & A00-B99 & Certain infectious and parasitic diseases \\
\hline$\|$ & C00-D48 & Neoplasms \\
\hline III & D50-D89 & $\begin{array}{l}\text { Diseases of the blood and blood-forming organs and certain disorders involving the } \\
\text { immune mechanism }\end{array}$ \\
\hline IV & E00-E90 & Endocrine, nutritional and metabolic diseases \\
\hline V & F00-F99 & Mental and behavioural disorders \\
\hline $\mathrm{Vl}$ & G00-G99 & Diseases of the nervous system \\
\hline VII & $\mathrm{H} 00-\mathrm{H} 59$ & Diseases of the eye and adnexa \\
\hline VIII & H60-H95 & Diseases of the ear and mastoid process \\
\hline IX & $100-199$ & Diseases of the circulatory system \\
\hline$x$ & J00-J99 & Diseases of the respiratory system \\
\hline$X I$ & K00-K93 & Diseases of the digestive system \\
\hline XII & LO0-L99 & Diseases of the skin and subcutaneous tissue \\
\hline XIII & M00-M99 & Diseases of the musculoskeletal system and connective tissue \\
\hline XIV & N00-N99 & Diseases of the genitourinary system \\
\hline$X V$ & O00-099 & Pregnancy, childbirth and the puerperium \\
\hline $\mathrm{XVI}$ & P00-P96 & Certain conditions originating in the perinatal period \\
\hline$X \mathrm{~V} I I$ & Q00-Q99 & Congenital malformations, deformations and chromosomal abnormalities \\
\hline XVIII & R00-R99 & Symptoms, signs and abnormal clinical/laboratory findings, not elsewhere classified \\
\hline XIX & S00-T98 & Injury, poisoning and certain other consequences of external causes \\
\hline$X X I$ & Z00-Z99 & Factors influencing health status and contact with health services \\
\hline
\end{tabular}

Note: ICD is the International Statistical Classification of Diseases and Related Health Problems from the World Health Organization. During the pre-program period, the ICD standard in Sweden changed from revision 9 to revision 10. We have classified the codes from the $9^{\text {th }}$ revision into the corresponding ICD-10 chapters 
Table 13 Summary statistics for the estimated propensity scores, the assessment of common support, and the sample size

\begin{tabular}{|c|c|c|c|c|c|c|c|c|}
\hline \multirow[b]{2}{*}{ Analysis } & \multicolumn{3}{|c|}{ Propensity score } & \multicolumn{3}{|c|}{ Outside common support } & \multicolumn{2}{|c|}{ Number of observations } \\
\hline & Mean & Min & Max & $p=1$ & $p=0$ & $p^{1}>p_{\max }^{0}$ & Total & Unique \\
\hline \multicolumn{9}{|l|}{ Main analysis } \\
\hline Participants $(D=1)$ & 0.104 & 0.002 & 0.717 & 0 & 0 & 1 & 2739 & 2738 \\
\hline Non-participants $(D=0)$ & 0.040 & 0.000 & 0.718 & 0 & 469 & $\mathrm{~N} / \mathrm{A}$ & 61,704 & 29,515 \\
\hline \multicolumn{9}{|l|}{ Sensitivity analysis $\left.\right|^{a}$} \\
\hline Participants $(D=1)$ & 0.128 & 0.002 & 0.898 & 0 & 0 & 1 & 2739 & 2738 \\
\hline Non-participants $(D=0)$ & 0.045 & 0.000 & 0.821 & 0 & 389 & $\mathrm{~N} / \mathrm{A}$ & 53,010 & 25,122 \\
\hline \multicolumn{9}{|l|}{ Sensitivity analysis $\|^{\mathrm{b}}$} \\
\hline Participants $(D=1)$ & 0.069 & 0.001 & 0.610 & 0 & 0 & 1 & 2853 & 2852 \\
\hline Non-participants $(D=0)$ & 0.028 & 0.000 & 0.544 & 0 & 401 & $\mathrm{~N} / \mathrm{A}$ & 95,403 & 41,096 \\
\hline \multicolumn{9}{|l|}{ Sensitivity analysis IIIC } \\
\hline Participants $(D=1)$ & 0.030 & 0.000 & 0.740 & 0 & 0 & 0 & 3010 & 3008 \\
\hline Non-participants $(D=0)$ & 0.003 & 0.000 & 0.768 & 0 & 2386 & N/A & $1,134,477$ & 486,029 \\
\hline \multicolumn{9}{|l|}{ Sensitivity analysis IVd } \\
\hline Participants $(D=1)$ & 0.099 & 0.000 & 0.600 & 0 & 0 & 3 & 1273 & 1273 \\
\hline Non-participants $(D=0)$ & 0.031 & 0.000 & 0.524 & 0 & 933 & $\mathrm{~N} / \mathrm{A}$ & 37,706 & 18,180 \\
\hline \multicolumn{9}{|l|}{ Sensitivity analysis Ve } \\
\hline Participants $(D=1)$ & 0.323 & 0.002 & 1.000 & 1 & 0 & 16 & 2,232 & 2231 \\
\hline Non-participants $(D=0)$ & 0.104 & 0.000 & 0.935 & 0 & 214 & $\mathrm{~N} / \mathrm{A}$ & 14,818 & 7091 \\
\hline \multicolumn{9}{|l|}{ Sensitivity analysis VIf } \\
\hline Participants $(D=1)$ & 0.092 & 0.001 & 0.420 & 0 & 0 & 0 & 2739 & 2738 \\
\hline Non-participants $(D=0)$ & 0.041 & 0.000 & 0.500 & 0 & 644 & N/A & 61,704 & 29,515 \\
\hline
\end{tabular}

aThe counterfactual case is changed from "non-participation" to "never-participation".

${ }^{b}$ The timing of disability coding is ignored.

'The disability coding is ignored altogether.

d Jobseekers who were not full-time unemployed at the time of registration at the PES are dropped.

' Both participation and non-participation is conditional on being employed in the month of November.

f Labour market histories earlier than the year immediately preceding the year of (potential) program participation are not included in the estimation of the propensity scores

Table 14 Summary of the assessments of the covariate balance (absolute standardised differences in means [ASDMs] and t-tests of equality in means) after inverse probability weighting (IPW)

\begin{tabular}{|c|c|c|c|c|c|c|c|c|c|}
\hline \multirow[b]{2}{*}{ Analysis } & \multicolumn{4}{|l|}{ ASDM } & \multicolumn{4}{|c|}{$p$-value ( $t$-test) } & \multirow[b]{2}{*}{$N^{c}$} \\
\hline & Mean & Min & Max & $>3^{a}$ & Mean & Min & Max & $<0.05^{b}$ & \\
\hline Main analysis & 0.516 & 0.000 & 1.763 & 0 & 0.803 & 0.377 & 1.000 & 0 & 198 \\
\hline Sensitivity analysis I $^{d}$ & 0.725 & 0.000 & 2.501 & 0 & 0.739 & 0.215 & 1.000 & 0 & 198 \\
\hline Sensitivity analysis $\|^{e}$ & 0.529 & 0.000 & 1.592 & 0 & 0.792 & 0.412 & 1.000 & 0 & 198 \\
\hline Sensitivity analysis $\| I^{f}$ & 2.893 & 0.000 & 56.244 & 44 & 0.404 & 0.000 & 1.000 & 21 & 198 \\
\hline Sensitivity analysis IVg & 0.590 & 0.000 & 2.325 & 0 & 0.846 & 0.450 & 1.000 & 0 & 198 \\
\hline Sensitivity analysis $V^{h}$ & 1.383 & 0.000 & 4.907 & 13 & 0.652 & 0.105 & 1.000 & 0 & 198 \\
\hline Sensitivity analysis VI' & 2.460 & 0.000 & 10.613 & 61 & 0.506 & 0.000 & 1.000 & 55 & 198 \\
\hline
\end{tabular}

a Number of covariates for which ASDM $>3$.

${ }^{b}$ Number of covariates for which a $t$-test for equal means yield a $p$-value $<0.05$.

${ }^{\mathrm{C}}$ Total number of covariates.

dThe counterfactual case is changed from "non-participation" to "never-participation".

eThe timing of disability coding is ignored.

${ }^{\mathrm{f}}$ The disability coding is ignored altogether.

9 Jobseekers who were not full-time unemployed at the time of registration at the PES are dropped.

${ }^{h}$ Both participation and non-participation is conditional on being employed in the month of November.

'Labour market histories earlier than the year immediately preceding the year of (potential) program participation are not

included in the estimation of the propensity scores 


\begin{abstract}
Abbreviations
ASDM: Absolute standardized differences in means; ATET: Average treatment effect on the treated; ATE: Average treatment effect; CI: Confidence interval; EUR: Euro; ICD: International Statistical Classification of Diseases and Related Health Problems; IPW: Inverse probability (of treatment) weighting; ILO: International Labour Organization; OECD: Organisation for Economic Co-operation and Development; PES: Public Employment Service; SIA: Social Insurance Agency; SE: Standard error; SEK: Swedish Krona; SUTVA: Stable unit treatment value assumption
\end{abstract}

\title{
Acknowledgments
}

The authors thank, for helpful comments and suggestions, Per Johansson, Pathric Hägglund, and seminar participants at IFAU and the Swedish Social Insurance Inspectorate. We would also like to thank the anonymous referee and the editor for the useful remarks. Responsible editor: Juan Jimeno.

\section{Funding}

The authors declare that they have no fundings to declare.

\section{Availability of data and materials}

The administrative register data used to generate the dataset that support the findings of this study are available from Statistics Sweden, but restrictions apply to the availability of these data and so are not publicly available. For replication purposes, the dataset is under certain circumstances available on request from the Institute for Evaluation of Labour Market and Education Policy (IFAU).

\section{Competing interests}

The IZA Journal of Labor Policy is committed to the IZA Guiding Principles of Research Integrity. The authors declare that they have observed these principles.

\section{Publisher's Note}

Springer Nature remains neutral with regard to jurisdictional claims in published maps and institutional affiliations.

Received: 8 May 2018 Accepted: 31 October 2018

Published online: 12 December 2018

\section{References}

Angelov N, Eliason M (2018) Factors associated with occupational disability classification. Scand J Disabil Res 20(1):37-49

Austin PC, Stuart EA (2015) Moving towards best practice when using inverse probability of treatment weighting (iptw) using the propensity score to estimate causal treatment effects in observational studies. Stat Med 34(28):3661-3679

Baert S (2016) Wage subsidies and hiring chances for the disabled: some causal evidence. Eur J Health Econ 17(1):71-86

Busso M, DiNardo JE, McCrary J (2009) New evidence on the finite sample properties of propensity score matching and reweighting estimators, IZA Discussion Paper No. 3998. IZA, Bonn, Germany

Caliendo M, Kopeinig S (2008) Some practical guidance for the implementation of propensity score matching. J Econ Surv 22(1):31-72

Caliendo M, Künn S, Schmidl R (2011) Fighting youth unemployment: The effects of active labor market policies, IZA Discussion Paper No. 6222. IZA, Bonn, Germany

Caliendo M, Mahlstedt R, Mitnik OA (2017) Unobservable, but unimportant? the relevance of usually unobserved variables for the evaluation of labor market policies. Labor Econ 46:14-25

Calmfors L, Forslund A, Hemström M (2004) The effects of active labor-market policies in Sweden: What is the evidence? In: Agell J, Keen M, Weichenrieder AJ (eds). Labor market institutions and public regulation. MIT Press, Cambridge. pp 1-63

Cervini-Plá M, Silva Jl, Castelló JV (2016) Estimating the income loss of disabled individuals: the case of spain. Empir Econ 51(2):809-829

Deuchert E, Kauer L (2017) Hiring subsidies for people with a disability-evidence from a small scale social field experiment. Int Labour Rev 156(2):269-285

Fitzenberger B, Sommerfeld K, Steffes S (2013) Causal effects on employment after first birth-a dynamic treatment approach. Labour Econ 25:49-62

Forslund A, Johansson P, Lindqvist L (2004) Employment subsidies-a fast lane from unemployment to work? Working Paper 2004:18. IFAU-Institute for Labour Market Policy Evaluation, Uppsala

Fredriksson P, Johansson P (2008) Dynamic treatment assignment: the consequences for evaluations using observational data. J Bus Econ Stat 26(4):435-445

Furdas M (2015) Empirical Evidence on the Effectiveness of Training and the Performance of Local Labor Agencies, PhD thesis. Albert-Ludwigs-Universität Freiburg im Breisgau

Gupta ND, Larsen M (2010) Evaluating employment effects of wage subsidies for the disabled-the danish flexjobs scheme, Working Paper 07:2010. The Danish National Institute of Social Research

Gupta ND, Larsen M, Thomsen LS (2015) Do wage subsidies for disabled workers reduce their non-employment?-evidence from the danish flexjob scheme. IZA J Labor Policy 4(1):10

Heckman JJ, Hotz VJ (1989) Choosing among alternative nonexperimental methods for estimating the impact of social programs: The case of manpower training. J Am Stat Assoc 84(408):862-874

Huttunen K, Pirttilä J, Uusitalo R (2013) The employment effects of low-wage subsidies. J Public Econ 97:49-60

Imbens GW (2004) Nonparametric estimation of average treatment effects under exogeneity: A review. Rev Econ Stat 86(1):4-29

Imbens GW, Wooldridge JM (2009) Recent developments in the econometrics of program evaluation. J Econ Lit 47(1):5-86

Jaenichen U, Stephan G (2011) The effectiveness of targeted wage subsidies for hard-to-place workers. Appl Econ 43(10):1209-1225 
Johansson P, Skedinger P (2009) Misreporting in register data on disability status: evidence from the swedish public employment service. Empir Econ 37(2):411-434

Lechner M, Vazquez-Alvarez R (2011) The effect of disability on labour market outcomes in germany. Appl Econ 43(4):389-412

Lechner M, Wunsch C (2013) Sensitivity of matching-based program evaluations to the availability of control variables. Labour Econ 21:111-121

OECD (2010) Sickness, Disability and Work: Breaking the Barriers: A Synthesis of Findings across OECD Countries. OECD Publishing, Paris

PES (2011) Revision of administrative support for the investigation and coding of impairments that entail reduced work capacity (revidering av handläggarstöd för utredning och kodning av funktionsnedsättning som medför nedsatt arbetsförmåga), Technical Report AFHS 24/2011, Stockholm, Sweden

Robins JM, Hernan MA, Brumback B (2000) Marginal structural models and causal inference in epidemiology. Epidemiol 11(5):550-560

Rosenbaum PR, Rubin DB (1985) Constructing a control group using multivariate matched sampling methods that incorporate the propensity score. Am Stat 39(1):33-38

Schünemann B, Lechner M, Wunsch C (2015) Do long-term unemployed workers benefit from targeted wage subsidies? Ger Econ Rev 16(1):43-64

Sianesi B (2004) An evaluation of the swedish system of active labor market programs in the 1990s. Rev Econ Stat 86(1):133-155

Statistics Sweden (2009) Labour market situation for disabled persons - 4th quarter 2008, 2009:3. Statistics Sweden, Labour Force and Work Environment Surveys Unit, Stockholm

Swedish Social Insurance Agency (2014) Analyzing the variation in the level of sickness absence - Essential explanations to the ups and downs of sick leave, 2014:17. Swedish Social Insurance Agency, Stockholm

van Ours JC (2004) The locking-in effect of subsidized jobs. J Comp Econ 32(1):37-55

\section{Submit your manuscript to a SpringerOpen ${ }^{\circ}$} journal and benefit from:

- Convenient online submission

Rigorous peer review

- Open access: articles freely available online

- High visibility within the field

- Retaining the copyright to your article

Submit your next manuscript at $\boldsymbol{\triangleright}$ springeropen.com 